\title{
Open innovation in specialized SMEs: the case of supercars
}

\author{
Andres Ramirez-Portilla
}

Department of Industrial Economics and Management, KTH Royal Institute of Technology, Stockholm, Sweden and Politecnico di Milano, Milan, Italy

$$
\text { Enrico Cagno }
$$

Politecnico di Milano, Milan, Italy, and

Terrence E. Brown

Department of Industrial Economics and Management, KTH Royal Institute of Technology, Stockholm, Sweden and Lulea University of Technology, Lulea, Sweden

\footnotetext{
Abstract

Purpose - The purpose of this paper is to explore the influence that adopting open innovation (OI) has on the innovativeness and performance of specialized small and medium-sized enterprises (SMEs). This paper also examines the adoption of OI within a firm's practices and models, and within the three dimensions of firm sustainability.

Design/methodology/approach - Survey data from 48 specialized SMEs manufacturing supercars were analyzed using partial least squares structural equation modeling. SmartPLS software was used to conduct a path analysis and test the proposed framework.

Findings - The findings suggest that high adoption of OI models tends to increase firm innovativeness. Similarly, the adoption of OI practices has a positive effect on innovativeness but to a lesser extent than OI models. The moderation results of innovativeness further show that OI models and practices can benefit the performance of SMEs. Specifically, two dimensions of performance - environmental and social performance - were found to be greatly influenced by OI.

Research limitations/implications - Due to parsimony in the investigated model, this study only focuses on OI adoption as practices and models without considering its drivers or other contingency factors.

Practical implications - This paper could help practitioners in SMEs better understand the benefits of adopting OI to be more innovative but also more sustainable.

Originality/value - This study contributes to the literature on the role of OI practices and models regarding the dimensions of firm sustainability performance by being the first paper to investigate this relationship in the context of small and medium manufacturers of supercars.

Keywords SMEs, Open innovation, Firm performance, PLS-SEM, Innovativeness, Supercars

Paper type Research paper
} 


\title{
Business Process Management Journal
}

\section{Open Innovation in Specialized SMEs: The Case of Supercars}

\author{
Andres Ramirez-Portilla,
}

KTH Royal Institute of Technology, Dept. Industrial Economics and Management Lindstedtsvägen 30 10044 Stockholm (Sweden), andres.ramirez-portilla@indek.kth.se

\section{Enrico Cagno,}

Politecnico di Milano, Dept. Management, Economics and Industrial Engineering, Piazza Leonardo da Vinci 32 - 20133 Milan (Italy), enrico.cagno@ polimi.it

Terrence Brown,

KTH Royal Institute of Technology, Dept. Industrial Economics and Management Lindstedtsvägen 30 10044 Stockholm (Sweden), andres.ramirez-portilla@indek.kth.se 


\title{
Open Innovation in Specialized SMEs: The Case of Supercars
}

\begin{abstract}
:
Purpose - The purpose of this paper is to explore the influence that adopting open innovation (OI) has on the innovativeness and performance of specialized small and medium-sized enterprises (SMEs). This paper also examines the adoption of OI within a firm's practices and models, and within the three dimensions of firm sustainability.
\end{abstract}

Design/methodology/approach - Survey data from 48 specialized SMEs manufacturing supercars were analyzed using partial least squares structural equation modeling (PLS-SEM). SmartPLS software was used to conduct a path analysis and test the proposed framework.

Findings - The findings suggest that high adoption of OI models tends to increase firm innovativeness. Similarly, the adoption of OI practices has a positive effect on innovativeness but to a lesser extent than OI models. The moderation results of innovativeness further show that OI models and practices can benefit the performance of SMEs. Specifically, two dimensions of performance - environmental and social performance - were found to be greatly influenced by OI.

Research limitations/implications - Due to parsimony in the investigated model, this study only focuses on OI adoption as practices and models without considering its drivers or other contingency factors.

Practical implications - This paper could help practitioners in SMEs better understand the benefits of adopting OI to be more innovative but also more sustainable.

Originality/value - This study contributes to the literature on the role of OI practices and models regarding the dimensions of firm sustainability performance by being the first paper to investigate this relationship in the context of small and medium manufacturers of supercars.

Keywords - Open Innovation, Practices, Models, Firm Performance, Small and Medium-sized Enterprises, Supercars, PLS-SEM.

Paper type - Research paper 


\section{Introduction}

Over the past decade, scholars and practitioners have shown increased interest in open innovation (hereafter referred to as OI) and at least another decade of research into OI theory and practice is expected (West et al., 2014). The term has permeated many disciplines from business process management (Niehaves and Plattfaut, 2011; Niehaves, 2010) to energy management (Cagno et al., 2015), creating a variety of research streams and areas within OI literature (Dahlander and Gann, 2010; Huizingh, 2011; Randhawa et al., 2016; Schroll and Mild, 2012; West and Bogers, 2013). Amongst the considerable amount of literature describing the adoption of OI, research focusing on small and medium-sized enterprises (SMEs) has gained considerable momentum. This is due to a number of initial studies (e.g., van de Vrande et al., 2009) recognizing the potential benefits such firms could achieve by adopting OI. In this regard, SMEs have been an interesting context in which to study OI because adopting more open notions and practices could help such companies deal with the 'liability of smallness' i.e. the inherent challenge of limited resources and competences (Parida et al., 2012). This also opens the debate to consider if OI could be more appropriate for SMEs than for large firms as smaller organizations are better at translating innovativeness into firm success (Handrich et al., 2015).

Recent studies have confirmed that the percentage of firms actually implementing the OI model (Chesbrough, 2003) has increased over the last decade (Cricelli et al., 2015). Despite the constant efforts of researchers to better understand this model, several of notions regarding OI, such as its determinants and consequences in specific contexts, remain unexplained (West and Bogers, 2013). Likewise, and from a practitioner's viewpoint, the practical potential of implementing OI to improve firm performance has been underexploited (Gambardella and Panico, 2014). In this regard, OI has been considered as a useful approach for SMEs to obtain additional resources and capabilities such as manufacturing or distribution (Bianchi et al., 2010). However, in the case of many manufacturing SMEs, these capabilities are already part of their current resources together with very specialized and deep knowledge that helps them to develop innovative products (Parida et al., 2011).

For this reason, sharper and more specific reasons why specialized manufacturing SMEs should adopt more open approaches remain unclear. For instance, if by definition every inbound practice in one firm generates a reciprocal outbound practice in another (Chesbrough and Crowther, 2006), many manufacturing SMEs may deem OI a risky option. This is because it would imply sharing some of their specialized resources with other firms (Ahn et al., 2015). Therefore, evidence of the benefits of adopting OI needs to outweigh the negative connotations of losing their distinctive resources and thus, one of their limited sustainable competitive advantages (Barney, 1991). This situation signals that to further understand the advantages of OI adoption by specialized SMEs, the focus should not only be on the potential to complement and extend firms' resources or increase their innovativeness through OI practices but also to study the influence of such practices on more specific dimensions of firm performance.

Adopting proper open and collaborative innovation practices could be a vital element in the strategy chosen by SMEs to thrive in industries with specialized levels of design requirements, $\mathrm{R} \& \mathrm{D}$, and technological intensity (Crema et al., 2014). A clear example is the case of small and medium manufacturers of supercars (SMMS) in the automotive industry. Despite their limited resources, these firms can lucratively design and produce vehicles with the same levels of design, technology and performance as those from large carmakers. These results are possibly attained due to the use of different OI approaches and collaborations with key partners. Such collaboration may allow SMMS to be more innovative while balancing their internal capabilities with those in their environment (Ketata et al., 2014) 
as well as gain access to marketing, manufacturing and relational complementary resources (Bianchi et al., 2014). While these ideas could explain the advantages of OI in terms of resources and innovativeness, much less is known about the impact that OI could have on other outcomes related to sustainability performance such as environmental impact, energy efficiency, labor practices, occupational safety, impacts on society, and products responsibility. Understanding this relation of OI with these types of social and environmental indicators is vital since they are also relevant to the sustainable performance of manufacturing SMEs (Bos-Brouwers, 2010). The purpose of this study is therefore to fill this gap by examining how the level of openness in terms of OI practices and models influences the innovativeness and different firm performance dimensions of specialized SMEs.

This study offers two original contributions. First, OI and firm performance constructs are characterized in a novel way in relation to existing OI literature. On the one hand, OI is studied with a much-needed approach complementing a practice-based perspective with other OI foundations (Vanhaverbeke and Cloodt, 2014). More precisely, OI adoption is rationalized with a combination of internal R\&D, inbound, and outbound practices (De Backer and Cervantes, 2008; Cagno et al., 2015). It is also rationalized in terms of content, partner, and innovation phase variety (Manzini et al., 2013). On the other hand, firm performance is characterized not only as economic performance but also with environmental and social indicators to contain the main dimensions of sustainability performance (Bos-Brouwers, 2010). Second, the study focuses on the context of SMMS as specialized SMEs, which have recently been depicted as a noteworthy setting in which to study OI ideas (Langner and Seidel, 2014). Moreover, this study argues that SMMS could confirm how even in mature traditional industries, specialized SMEs can play the important role of market explorers or as technical specialists (Chesbrough, 2010), creating innovations with a great diffusion potential.

The remainder of the paper is structured as follows. Section 2 introduces the theoretical foundation, the conceptual model, and the proposed hypotheses based on literature mostly focusing in the influence that OI constructs could have on the performance of SMEs that follow a specialization approach. Section 3 describes the research methodology including the measurement of the variables and the data collection process. Section 4 provides the statistical analyses and results of the measurement and structural models. The subsequent section presents a discussion of the findings and its implications for theory and practice. Research limitations and suggestions for future research are provided in the final section.

\section{Theoretical background and conceptual framework}

The literature on practices, models, and other notions of OI is vast. Therefore, our review of the relevant literature to support the theoretical framework was delimited by the elements proposed by Huizingh (2011) to understand better OI phenomena. These elements are the answers to the questions of when (the context dependency of OI), what (the content of OI), and how (the process of OI). First, we reviewed literature that considers the context when an SME choses to specialize in a type of product such as in the case of supercars and has the alternative to adopt OI to offset some of the limitations of its specialization strategy. Second, we have narrowed the literature that recognizes mainly the content of OI as a combination of innovation practices but also as a set of interacting models with different degrees of varieties. Third, we look at studies that provided insights about how the process of adopting OI could influence a firm's innovativeness level but also other relevant dimensions of its performance. Therefore, in the course of this section we will focus mainly on recognized and recent studies related with the abovementioned criteria that limited our review on OI literature. 


\subsection{Openness relevance for specialized SMEs}

The term specialized SME is generally understood to mean an SME that is focused on offering few specific products or services. However, the term embodies a multitude of concepts that are relevant to the firm's innovation activities which signal the need to elaborate more about it. In this regards, SMEs can regularly engage along a continuum of specialization and diversification activities rather than as two independent choices (Lai et al., 2010). In fact, most of them start with a 'focusing process' in which they only specialize in specific technologies, products, and knowledge domains for many years before starting a 'widening process' of their innovative activities (Breschi and Malerba, 1999). Hence, a significant number of SMEs could be considered specialized either as a temporal choice or as a continuous strategy. Moreover, because the terms of specialization and diversification can be related to different notions, the term of specialized SMEs can also be studied from various angles. For instance, a firm's level of innovation can be linked to the generic, specialized, and cospecialized complementary assets it owns or employs (Teece, 1986). Specialization can also refer to a dimension related to organizational structure (Ihl et al., 2012) or a more tangible concept such as product or technological specialization (Lichtenthaler, 2008). Therefore, the specialization level of an SME does not refer only to the organization of its business units, but it can also be linked to the nature and complexity of the products it produces (Kaulich, 2012). A good example is the case of some SMEs in luxury industries, which can have an international diversification but they could also be considered as specialized firms because of its capacity to manufacture unique, innovative products (Brun and Castelli, 2013; Ponticelli et al., 2013). Thus, an SME could adopt a specialization or diversification approach in several aspects and activities if prudently considering the core skills or resources needed for each case (Rumelt, 1982).

More importantly, choosing any of these approaches is of vital importance for certain types of firms because while the dichotomy specialization/diversification could be less risky for large firms due to their available resources, for SMEs it could be the difference between survival or extinction (Crema et al., 2014; Parida et al., 2012; van de Vrande et al., 2009). Studies have shown that SMEs are more likely to develop relatively narrow specializations than larger firms (Zhao, 2014) and thus, it is not surprising that many SMEs prefer specialization over diversification approaches. Furthermore, diversification may not always be a key strategy chosen by SMEs because this is mostly triggered in firms by excess capacity of resources such as human capital (Penrose, 1959), which many SMEs do not always have. Moreover, even though an SME could have very specialized knowledge, in order to be an innovator and not only an imitator, it would likely need to access other specialized complementary assets and/or capabilities through the expansion and diversification of its regular activities (Teece, 1986). However, not all SMEs may be keen to undertake these diversification activities, including collaborations with larger firms, because of the associated high transaction costs (Jang et al., 2016; Parida et al., 2012). Similarly, a strategy of diversifying into unrelated businesses could involve resource sharing with one or more distinct firms (Rumelt et al., 1994) with the risk of losing their relative unique sources of competitive advantage (Barney, 1991; Rumelt, 1982). For these reasons, the idea of SMEs with certain levels of product, technology and practices specialization makes sense from both theoretical and practical viewpoints.

Moreover, an SME's level of specialization involves certain fundamentals related to its innovativeness. First, SMEs are less likely than large firms to possess all the relevant specialized capabilities and assets within their boundaries, and so they often need to decide whether trying to build them or trying to develop relationships with other organizations that own the required specialized assets (Teece, 1986). In 
other words, even specialized SMEs are also likely to face often the strategic make-or-buy decision related to fostering and developing mechanisms to absorb effectively new technologies in order to be more innovative (Brem et al., 2014). Second, even though specialized manufacturing SMEs risk having a smaller customer base and thus a smaller source of potential new ideas, the sophistication of their products allows them to service a niche market with more specific requirements and needs (Padula et al., 2015). Despite the lack of open standards in some mature manufacturing industries, like the automotive or semiconductor industries, numerous entrepreneurial SMEs can design and manufacture products due to their vertical specialization capabilities (Funk and Luo, 2015). Certainly, specialization may pose some issues related to the incompatibility of efforts to organize a distributed search of external knowledge (Ihl et al., 2012). However, it is reasonable to consider that by adopting different OI activities involving external partners, SMEs could offset some of the limitations of their specialization, as these activities could help them diversify their opportunities by searching, exploring, and exploiting internal and external knowledge (Ahn et al., 2015).

In fact, since the concept of OI was proposed (Chesbrough, 2003), it has been recognized that firms do not necessarily need to have a clear-cut closed or open approach towards innovating but rather a continuum covering varying degrees of openness (Dahlander and Gann, 2010). In this sense, OI provides the opportunity for specialized SMEs to balance their innovation focus between using closed/open and narrow/broad approaches. The notion of finding this equilibrium could be inferred from recognized OI definitions that have also evolved to simultaneously specify the scope of the concept (West et al., 2014). Considering this, SMEs could be better off by not concentrating solely on either exploring or exploiting approaches but rather on maintaining an effective balance between the two (March, 1991). This balance could be achieved by developing certain resources and innovation capabilities (Boer et al., 2006) or through the proportional adoption of certain open processes or archetypes (Gassmann and Enkel, 2004). Furthermore, the idea of a firm balancing the exploration and exploitation processes across boundaries as well as the purposive inflows and outflows of knowledge is at the core of the OI model and its related practices (Chesbrough, 2003; Chesbrough et al., 2006; Huizingh, 2011). Therefore, these fundamental ideas about opening the innovation process signal the potential for specialized SMEs to diversify their innovation approaches and create value off by adopting OI.

More specifically, it is in an OI context that an exchange of knowledge through different collaborations with partners across boundaries can materialize. In turn, these collaborations could help SMEs to diversify their innovation routes and innovation practices (Ahn et al., 2015) despite choosing a specialization approach for their products and/or services. Indeed, as with many other social and organizational phenomena, innovation management practices are contingent upon the type of context in which they are applied (Aas et al., 2015; Huizingh, 2011; Ortt and van der Duin, 2008). Hence, the notion that an SME diversifies its practices when adopting OI could contrast with a firm's specialization approach in terms of its products, technologies or its organizational structure (Ihl et al., 2012). Therefore, even though the relevance of a diversification approach versus a specialization one has been discussed more often as a strategy for economic development (Kaulich, 2012), it can also have relevant implications for an SME's innovation strategy involving external actors. To illustrate, while specialization in certain products or technologies may close new revenue streams, it can also help firms to not be exposed to new risks and unknown liabilities (Teece, 2007) allowing them to pursue other opportunities to innovate.

Therefore, it could be said that SMEs can continue to specialize in innovating only in their known products or the markets they already serve to avoid exposure to new industry threats while simultaneously 
adopting OI to build relationships that can contribute to the diversification of their innovation paths (Ahn et al., 2015). Even though the evidence in the literature on the link between the specialization of an SME and its adopted OI approaches is limited, this relationship can be fairly established. For instance, a few studies suggest that firms that are highly specialized in their technologies use external technology acquisition less than firms with a highly diversified technology portfolio (Lichtenthaler, 2008). Other studies have concluded that it is expected that SMEs with specialization of products or technologies rely more on external technology exploitation than more diversified ones (Teece, 1986) as well as developing more partnerships with firms that have the specialized resources in innovation that they need but do not possess (Teece et al., 1997). Considering the above, depending on the openness SMEs adopt, they could become not only more innovative but also more vertically integrated, or technology specialists (Padula et al., 2015). Therefore, by adopting more open and collaborative practices with other actors, specialized SMEs can also become technical specialists or explorers for larger firms (Chesbrough, 2010).

A good example of the above is the case of small and medium-sized manufacturers of supercars (SMMS). Despite their limited resources, SMMS can leverage several practices related to OI, allowing them to produce supercars i.e. one-of-a-kind vehicles with high levels of design, performance and the latest available technology (Cheetham, 2006). Perhaps more surprising is the fact that these types of firms, as many others in the automotive industry (Schuster and Brem, 2015), have been collaborating with external partners and even practicing outbound innovation activities for decades. SMMS have proven to be a source of innovation for technology later incorporated into mainstream vehicles due to safety, performance, regulatory, and economic drivers. Clear examples of this are the disc brakes, five-speed gearboxes and four-wheel-drive originally developed for supercars but now used widely (Zapata and Nieuwenhuis, 2010). Moreover, some of studies highlight SMMS directly and indirectly as an attractive research context to investigate the validity and implementation of OI and its influence. In particular, several studies of OI in the automotive industry (Ili et al., 2010; Karlsson and Sköld, 2013; Oh and Rhee, 2010; Sierzchula et al., 2015) have stressed practices where large OEMs repeatedly involve mediumsized car designers in their innovation processes. Similarly, but using firm-level analysis, a number of case studies have portrayed the extent to which OI has involved the collaboration of medium-large supercar design firms (Lazzarotti et al., 2013; De Massis et al., 2012). More recently, the case of Local Motors, a small supercar manufacturer producing open-source vehicles based on its online community, has been used to investigate OI practices supporting the identity of the firm among community members (Langner and Seidel, 2014). These studies support the idea that investigating the openness adopted by SMMS could provide further insights to understand the relevance of OI for specialized SMEs but also whether an SME adopting OI could overcome some shortcomings related to a high degree of specialization.

\subsection{Hypothesis development}

The significance of SMEs within the economy and in terms of innovation is beyond doubt. Even though SMEs represent $99 \%$ of the most innovative firms (Verheugen, 2003), they do not escape the challenge to continuously innovate to remain competitive. This challenge is often influenced by context characteristics, in which being small inherently relates to facing a lack of resources to develop and commercialize new products in-house. Hence, smaller firms are often inclined or obliged to collaborate with other organizations (Parida et al., 2011). These collaborations often translate into multiple opportunities for SMEs, and thus there has been a growing trend among these firms towards adopting open innovation practices and models (van de Vrande et al., 2009). However, the adoption of OI by firms is closely linked 
to the strategy they pursue and the choices they make (Barge-Gil, 2013). Therefore, the variety of the degree of openness in SMEs from manufacturing industries could be explained by the configurations of OI activities they adopt (Idrissia et al., 2012). Two configurations of OI adoption are often recognized in the literature: practices and models.

First, a common way for firms to operationalize open innovation is through three main types of practices: inbound, outbound, and coupled activities (Gassmann and Enkel, 2004). Most research on OI has focused on inbound and outbound activities since coupled activities are less frequently distinguished (Bianchi, Cavaliere, et al., 2011). The adoption of inbound or outbound practices does not imply that a firm should stop its established internal innovation. Instead, the OI model suggests that the internal innovation in a firm - often characterized as its internal R\&D practices - should be balanced with other sources of knowledge (Huizingh, 2011). However, before looking for innovative solutions or increasing innovativeness through external sources of technology and knowledge, a firm must have strong R\&D capabilities (Veugelers, 1997; Xiaobao et al., 2013). Therefore, internal R\&D is a key element in the OI model that together with inbound and outbound practices can help firms to increase their innovativeness and performance (Schroll and Mild, 2011; Xiaobao et al., 2013). Some studies have shown the usefulness of considering an integrated perspective that analyses the combination of inbound and outbound practices to understand better their effects (Mazzola et al., 2012; Michelino et al., 2014; Sikimic et al., 2016). Other authors have included or assessed the use of internal $R \& D$ activities to provide a more complete picture of the practices directly related to OI (De Backer and Cervantes, 2008; Brunswicker and Vanhaverbeke, 2014; Caird et al., 2013; Yun et al., 2013). Thus, a note of caution here is appropriate: although internal $\mathrm{R} \& \mathrm{D}$, inbound, and outbound practices are conceptually different, due to its direct link to the OI model, in this study the three of them are encompassed under a construct labeled as 'Open Innovation Practices.'

Likewise, in the case of SMEs, there is evidence that shows how these firms have been engaging in several OI practices for many years to meet customer demands and be more innovative (van de Vrande et al., 2009). Also, SMEs' internal R\&D activities together with particular OI practices can play a direct and critical role in a firm's innovation output and thus its level of innovativeness (Cheng and Huizingh, 2014; Kim and Park, 2010). This is specially true in the automotive industry where an internal lack of adequate R\&D skills to successfully drive new radical product development would force a firm to obtain these skills from external partners (Gerhard et al., 2008). In line with the above, while some particular inbound practices in SMEs can be linked to radical innovation outputs, others are linked to incremental innovation levels (Parida et al., 2012). Similarly, researchers have found that several practices related to knowledge search, acquisition, and sourcing positively influence indicators related to firm innovativeness (Ebersberger et al., 2012; Liao and Barnes, 2015). Moreover, numerous inbound and outbound OI approaches involve knowledge-sharing practices, which can also increase a firm's innovative capacity (Zanzouri and Francois, 2013). Finally, and related to the context of specialized SMEs, it has also been found that firms that choose a less diversified strategy are inclined towards OI practices to increase their level of innovativeness (Crema et al., 2014). Therefore, although the influence of adopting OI can be different depending on firm size (Barge-Gil, 2013), there is clear evidence showing the positive effect that practices directly related to OI can have on the innovativeness level of SMEs (Corral de Zubielqui et al., 2016; Schuster and Brem, 2015; Xiaobao et al., 2013). Thus, we would expect that:

H1: Open innovation practices are positively related to the innovativeness of specialized SMEs. 
Second, OI between SMEs and large firms can be implemented and managed through various approaches of cooperation, being OI models the most developed ones (Jang et al., 2016). Therefore, it can be expected that open innovation as a model can have different elements organized in a variety of arrangements and strategies (Crema et al., 2014; Lazzarotti et al., 2010). This diversity can support the proposal of OI models from a business model perspective (Braun, 2015) to more specific ones (Michelino et al., 2015). Indeed, some ideas behind the adoption of OI models have been more accepted as influencing firms' innovativeness than others (Dahlander and Gann, 2010; Schroll and Mild, 2012). For instance, researchers recurrently use the idea of breath and depth of collaborations with external partners proposed by Laursen and Salter (2006) to examine the influence of OI on firms' innovativeness. Thus, using the notion of partner variety as originally proposed (see e.g. Martini et al., 2012) or an adaptation of it (see e.g. Schroll and Mild, 2011) has been useful to understand one of the dimensions of OI models. Moreover, this pattern also holds true for SMEs that implement OI to interact with other actors to increase their innovativeness by complementing their human capital (Niehaves, 2010) through informal collaborations (Niehaves and Plattfaut, 2011) or formal alliances (Zhao, 2014).

Researchers have adapted a variety of scales and indicators to measure OI models, suggesting the possibility of characterizing OI with a mix of them (Schroll and Mild, 2012). For example, Lazzarotti and Manzini (2009) and Lazzarotti et al. (2010, 2011a) examined OI models as a combination of number and type of partners with number and type of innovation phases, finding a positive relationship with firm innovativeness. Similarly, Bianchi et al. (2011) combined types of partner, organizational modes and phases of the $R \& D$ process to investigate the appropriateness of these concepts in an OI model. Certainly OI models could be investigated from several angles depending on the contextual factors chosen (Lazzarotti et al., 2011b, 2015; Michelino et al., 2014); however, a reductionist or integrated approach to study OI can be equally valuable (Vanhaverbeke and Cloodt, 2014). It seems then that indicators measuring the extent and intensity of collaborations with different degrees of variety could also be useful to understand the influence of OI on an SME's level of innovation (Ahn et al., 2015; Dahlander and Gann, 2010). Considering these ideas, i.e. partner variety (Laursen \& Salter, 2006) and innovation phases variety (Lazzarotti and Manzini, 2009), a third dimension of openness related to content variety (Bengtsson et al., 2015; Manzini et al., 2013) has recently been proposed to study the role of OI models on the innovation performance of firms. Therefore and similarly to OI practices, there is favorable evidence showing that adopting OI models can have a positive influence on the innovativeness level of firms in general (Chiang and Hung, 2010; Enzing et al., 2011; Lazzarotti et al., 2015), but also of SMEs (Grundström et al., 2013; Idrissia et al., 2012; Vahter et al., 2015). Thus, we posit the following:

H2: Open innovation models are positively related to the innovativeness of specialized SMEs.

It needs to be recognized that one criticism that OI continues to have is the lack of a reconciliation of terms used within the literature (West and Bogers, 2013). This downside needs to be addressed to clarify OI as a paradigm for understanding innovation and its outcomes (Chesbrough and Bogers, 2014). An interesting case could be seen by comparing the adoption of OI models with the adoption of OI practices. A starting point for this differentiation could consider the most recognized OI definitions (West et al., 2014). For instance, the first OI definition balanced external and internal elements (Chesbrough, 2003a) while its revised version included a balance between two flows of knowledge (Chesbrough, 2006). In subsequent definitions, other complementary approaches - like multiple channels (West and Gallagher, 2006) or a balance between mechanisms (Chesbrough and Bogers, 2014) - were stressed. All of these and other definitions implicitly consider that OI models and OI practices are not mutually exclusive. 
However, and more importantly, it is important to consider that different OI practices more often involve a variety of actors, phases and content, and not the other way around (Lazzarotti et al., 2010). Therefore, it can be suggested that, even though adopting both configurations of OI notions could have an influence on firm innovativeness, the role of OI models is expected to be larger. Therefore, it is expected that:

H2a: Open innovation models are more positively related than open innovation practices to the innovativeness of specialized SMEs.

Traditionally, innovativeness due to innovations and innovating activities is seen as a key factor influencing firm performance and therefore firm success (Vij and Bedi, 2015). Consequently, firm innovativeness - including the introduction of innovations and new technologies - is considered a good predictor of business success, especially if it has been influenced by R\&D and other innovation activities (Handrich et al., 2015). In the case of SMEs, the level of innovativeness can make the difference between operating at a local level or internationalizing across known and new markets (Dai et al., 2014). Based on these ideas, it is also reasonable to assume that firm innovativeness that has been triggered or enhanced by OI should also play a vital role in the overall business performance (Martini et al., 2012). Unfortunately, concerning the effectiveness of innovativeness driven by OI, it is not fully clear yet if being innovative due to openness always has positive implications in terms of economic performance (Chen et al., 2011; Manzini et al., 2013; Schuster and Brem, 2015). However, some recent and robust studies have provided evidence to a satisfactory extent showing a positive relationship between higher levels of innovativeness due to OI adoption and economic performance (Barge-Gil, 2013; Crema et al., 2014; Lichtenthaler, 2009; Verbano et al., 2013).

However, even though economic performance is widely used to evaluate the profitability and success of a business, there are other equally relevant dimensions used to evaluate firm performance (Bos-Brouwers, 2010). For instance, in recent times, numerous firms, including SMEs, have been focusing considerably on achieving targets related to environmental and social challenges to reach an overall optimal performance (Smith et al., 2010). Moreover, the notion of sustainable development is currently and increasingly being related to managing innovation, which can support the achievement of sustainability performance (Hansen et al., 2009). In fact, recent studies in manufacturing SMEs have examined the positive relationship between adopting OI, firm innovativeness and environmental performance indicators (Cagno et al., 2015; Ramirez-Portilla et al., 2014). Similarly, other studies have remarked that manufacturing SMEs should enhance their overall innovativeness through more open and collaborative approaches because this could help improve their sustainability dimension by balancing social, environmental, and economic levels (May et al., 2012; Prabawani and Barret, 2013). This idea seems logic since being more innovative through OI could help an SME to complement its internal capabilities with the ones of its environment for creating sustainable innovation (Ketata et al., 2014), but also innovating through cooperation with different stakeholders could provide opportunities to improve the sustainability performance of SMEs (Bos-Brouwers, 2010). Thus, we propose the following:

H3: Innovativeness is positively related to the firm performance of specialized SMEs.

The above-mentioned hypotheses and the relation of their related concepts are illustrated in Figure 1. In the next section, a detailed description of the operationalization and measurement of the concepts inside each construct is presented. 


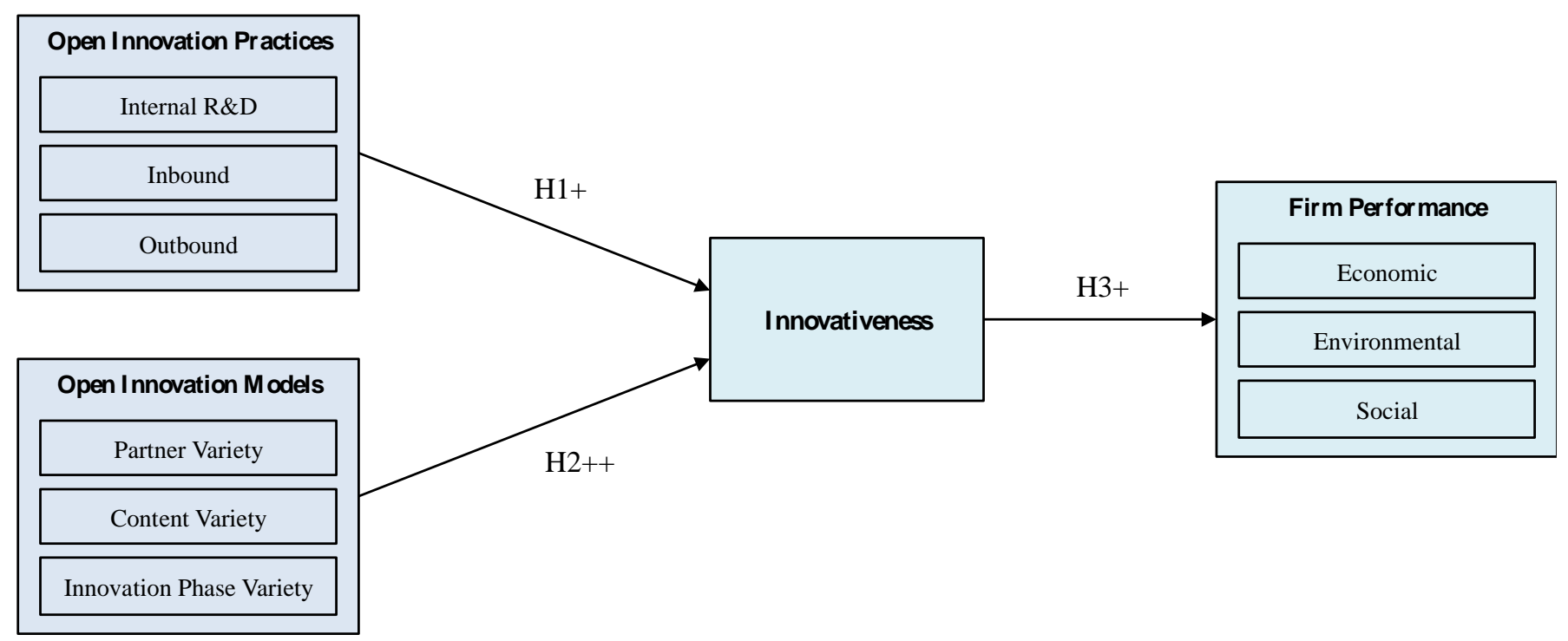

Figure 1. Conceptual framework

\section{Methodology}

\subsection{Sample and data collection}

To collect the data, a questionnaire survey was developed following guidelines on survey design (Fink, 2003; Forza, 2002) and applied during the first quarter of 2015. One of the main drawbacks of the sampling process was the uncertainty of the total population of SMMS. A figure of the total operational SMMS worldwide was not available, even from associations like the MIA (Motorsport Industry Association) or the FIA (Fédération Internationale de l'Automobile). Therefore, the three authors and two external persons conducted an extensive manual search on the internet from 2013 to 2015. For the practical purpose of contacting the firms for this study, an SMMS was only considered if it had an international profile i.e. its official website had at least some information in English. Another criterion was that the SMMS could be reached by any means including e-mail, telephone or its corporate account on any social media platform i.e. Facebook, Twitter, LinkedIn, etc. The initial search yielded 163 firms with an international SMMS profile; however, after discarding tuning services and low-volume supercar makers with vast economic resources e.g. McLaren, the final sample consisted of 143 firms, located mostly in Europe. The complete list of the sampled firms together with their manufacturing locations are shown in Figure 2. 


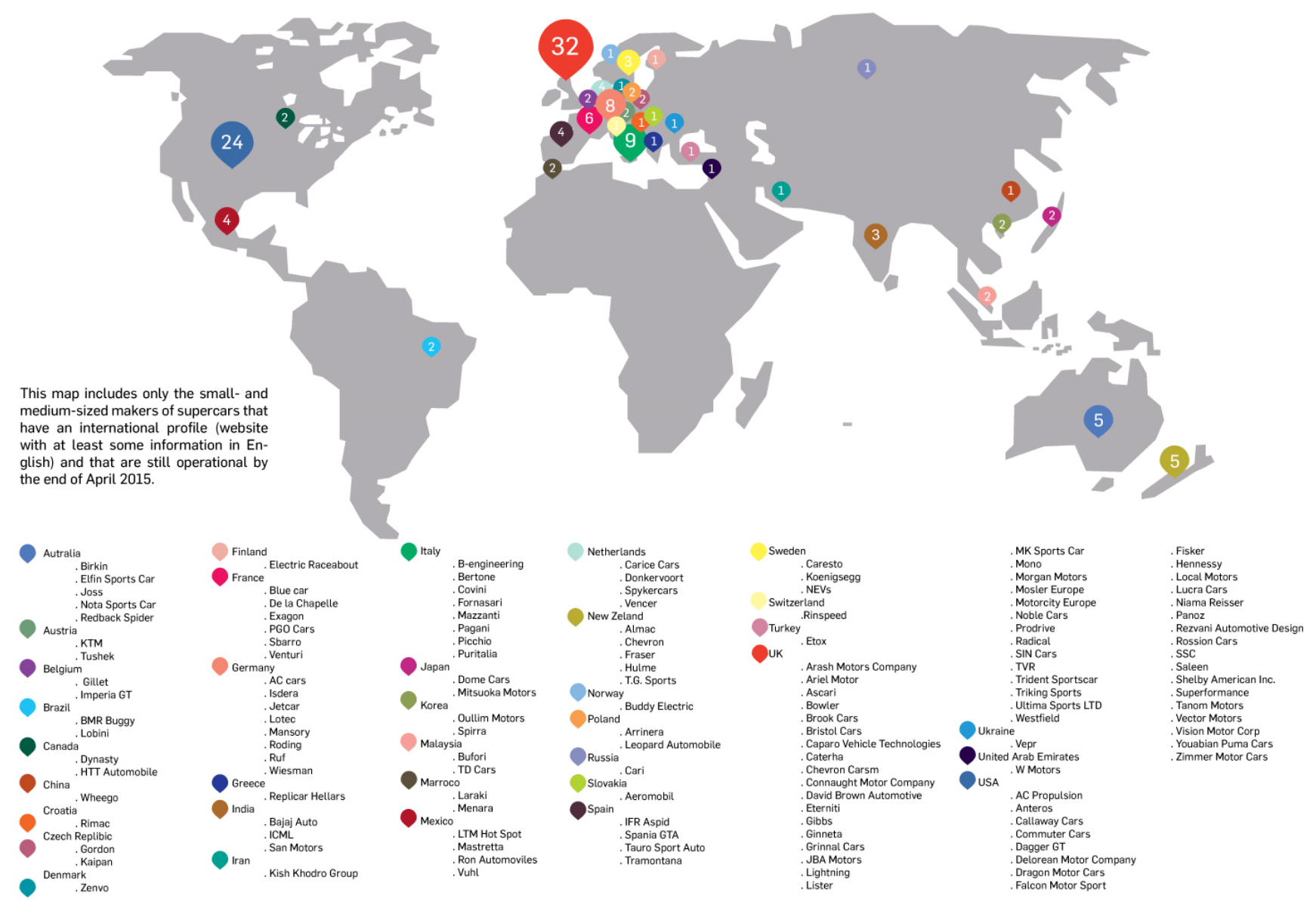

Figure 2. Small and medium manufacturers of supercars (SMMS) sampled for this study. SMMS with an international profile were still operational by the end of April 2015.

Due to the advantages of collecting data through online methods (Forza, 2002), data were collected via an online questionnaire. The target respondents of the survey were firms' owners, top management and other key employees highly involved in their firm's innovation process. The questionnaire was designed and administered in English as it is a baseline language spoken by the target respondents i.e. SMMS with an international profile. In any case, a double translation method (see e.g. Cheng and Huizingh, 2014) was only possible for Spanish and Italian. To offset this limitation, we enabled a multi-language support tool in the online survey website which allowed the questions to be translated into other languages.

After three reminders, 48 firms answered the survey in full, which represents a response rate of $33.6 \%$. From the 48 responses obtained, 27 were from firms located in English-speaking countries (Australia, Canada, New Zealand, UK, and USA), seven from countries in the top 15 ranking of the EF English Proficiency Index (Austria, Germany, Malaysia, Netherlands, and Sweden), 10 from countries where the translated questionnaires were used (Mexico, Spain, and Italy), and four from other countries (Brazil, Croatia, France, and the United Arab Emirates), predicting a minor response bias due to a language barrier. In any case, the authors recognized that a language limitation in a survey could influence the firms responding to it. Thus, the non-response bias was assessed by comparing early and late respondents' answers (Cheng and Huizingh, 2014). Using a t-test, the data did not show any significant difference at the 0.05 alpha level between early respondents $(43.7 \%$ answering before the first reminder) and late 
respondents in terms of country (i.e. English language level), number of employees, age, innovativeness, or in any of the three dimensions that constitute the variables of OI models, OI practices, and firm performance, respectively.

\subsection{Measurement of variables}

To ensure content validity in studies using survey and SEM methods, some previous authors used constructs that were well-grounded in the literature (e.g. Aloini and Martini, 2013; Aloini et al., 2011; Liao and Barnes, 2015), while others chose to pre-test the questionnaire with groups of practitioners and academics (e.g. Storey and Kahn, 2010). In this study, we used a mixed approach to establish content validity. Firstly, to explore the potential degree of openness in this type of firm, we conducted two pilot case studies of SMMS - a cross-sectional study in Sweden and a longitudinal one in Mexico (RamirezPortilla, Cagno and Brown, 2014). Secondly, we only considered variables and constructs derived from recognized literature and previous empirical studies such as the OI Survey on manufacturing firms in Europe (Bengtsson et al., 2015; Manzini et al., 2013). Finally, we requested that the two firms used for the pilot studies, together with two other targeted firms and a group of scholars, help us validate the quality of the survey questionnaire to ensure content validity.

The survey questionnaire included 21 questions resulting in 98 items. Not all of them were used in this study. The items regarding demographics included open-ended or multiple-choice questions. All of the other items related to the studied constructs were measured by perceptive five-point Likert scales, which are all reflective with the exception of the performance variables. Depending on the question, the scale of the answers range from $1=$ 'strongly disagree / never / no influence / much worse', to 5 = 'strongly agree / very often / major influence / much better', respectively. All of the items that were included to measure the variables in each construct are listed in the Appendix.

\section{Open Innovation Practices (OIP)}

We measured OIP as a second-order component through three dimensions of innovation practices directly related to the OI model: internal R\&D, inbound, and outbound (De Backer and Cervantes, 2008; Cagno et al., 2015). We took items to gauge internal R\&D practices from the Community Innovation Survey - CIS (Eurostat, 2013) and the Oslo Manual (Mortensen and Bloch, 2005). To measure OI inbound practices, we adapted questions from the CIS, the Open2-Innova8ion Tool (Caird et al., 2013), OECD and EU reports (De Backer and Cervantes, 2008; Salmelin, 2013) and Lazzarotti et al. (2010). For the outbound practices, we adapted items from Ili et al. (2010), Schroll and Mild (2011), Bianchi et al. (2011), and Cheng and Huizingh (2014).

\section{Open Innovation Models (OIM)}

The literature has depicted several alternatives to measure the models adopted by firms to open their innovation funnel. In this study, we have opted to use the perspective of OIM proposed by a large group of researchers (Manzini et al., 2013). Thus, we have measured OIM as a second-order component through three dimensions of openness variety: partner, innovation phase and content. We adopted previous scale items to measure partner variety from Laursen and Salter (2006), and for the innovation phase variety we took items from Lazzarotti and Manzini (2009) and Lazzarotti et al. (2011). For content variety, we adapted items from Azadegan and Dooley, (2010), He and Wong (2004), and Oh and Rhee (2010), which have recently been examined by Bengtsson et al. (2015). 


\section{Innovativeness (INNO)}

Firm innovativeness has been defined in a fairly consistent way as a firm's propensity to innovate, develop new products or adopt innovations (Garcia and Calantone, 2002). However, its measurement has been less standardized and, accordingly, numerous items could be used to gauge it. We took inspiration from the survey by Manzini et al. (2013) to measure the degree of innovativeness of a firm by adapting items from Gassmann and Enkel (2004), Kolk and Püümann (2008), Dahlander and Gann (2010) and Lazzarotti et al. (2011).

\section{Firm Performance (FP)}

Even though FP can be examined with several dimensions, economic and financial indicators are usually used to measure the influence of innovation on firm success (Handrich et al., 2015). Because SMEs could be susceptible to disclosing financial indicators, obscuring a picture of its economic situation (Verheugen, 2003), we followed a similar approach to Cheng and Huizingh (2014) by asking the firms to rate their economic performance with respect to their own performance in the last three years and with respect to their competitors. Additionally, we measured the environmental and social performance with questions inspired from Ketata et al. (2014) and from the Global Reporting Initiative (2006) to consider FP as a second-order component measuring the three pillars of sustainability performance.

\section{Analysis and results}

We followed the main phases of the SEM methodology (Hair et al., 1998), similarly to other studies investigating the relation between practices and performance (Aloini and Martini, 2013). These phases include specifying a theoretical model, defining a structural and measurement model, testing the model and interpreting the results. In general, we chose an SEM method because it is adequate to test relationships where a dependent variable in certain hypotheses becomes an independent variable in successive ones (Bianchi et al., 2014). However, this study used partial least squares structural equation modeling (PLS-SEM) instead of the more widely applied covariance-based SEM (CB-SEM) approach. We chose PLS-SEM over CB-SEM for numerous reasons. The former requires fewer data to estimate loadings in comparison to the latter, thus it is appropriate for small sample sizes and complex models (Hair et al., 2014). Also, PLS-SEM can be a silver bullet in research situations when the data are abnormally distributed or it is necessary to estimate models with many indicators and relationships (Hair et al., 2011). Lastly, the predictive focus of PLS-SEM can be useful to study sources of competitive advantage (Hair et al., 2014), successful drivers of innovation (Storey and Kahn, 2010), and the role that certain practices can have in supporting OI (Podmetina et al., 2013). Considering these ideas, we used SmartPLS software (Ringle et al., 2005) to test the measurement and the structural model described next.

The 48 responses obtained were considered appropriate to conduct all of the related analyses in this study. This amount of responses seems suitable for the small population of known SMMS, if considering a normal approximation to the hypergeometric distribution with a confidence level of $90 \%$ and a sampling error of $\pm 10 \%$ (Morris, 2004). Moreover, because six is the maximum number of indicators in each construct in the analyzed PLS path structural model, 48 responses are appropriate as the minimum sample size required to detect minimum $\mathrm{R}^{2}$ values of 0.50 in any independent variable for significance levels of $5 \%$, assuming a statistical power of $80 \%$ is 47 (Cohen, 1992).

\subsection{Measurement model test}


Before testing the hypotheses in the structural model, it is vital to test a series of assumptions to evaluate the measurement model. Thus, we assured content validity with the mixed approach previously described. Because the survey respondents answered questions on the dependent and independent variables at the same time, the common method variance (CMV) should be considered (Podsakoff et al., 2003). Considering this potential issue, we separated the survey items measuring the predictors and the criterion variables to reduce the risk of common method bias (Dai et al., 2014). However, to prevent CMV more effectively, we used Harman's single-factor test where an unrotated exploratory factor analysis included all variables items of OIP, OIM, INNO and FP. The percentage of variance explained by four factors based on eigenvalues greater than 1 is $56.23 \%$ while a single unrotated factor accounts for $37.18 \%$ of the total variance. Because a single factor does not explain the majority of the variance, common method bias does not appear to affect the data (Lowry and Gaskin, 2014; Podsakoff et al., 2003).

To continue confirming the reliability and validity of the measurement model, we followed recognized criteria reported in literature (Aloini et al., 2011; Liao and Barnes, 2015; Storey and Kahn, 2010). Thus, to examine the reliability of the items in each first-order variable, we calculated the Cronbach's $\alpha$ coefficients. In all cases, the coefficient was found to be greater than 0.7, indicating high reliability (Hair et al., 1998). Additionally, we estimated the composite reliability (CR) for all measured variables resulting in values between 0.82 and 0.92 , which are considered between the acceptable levels for internal consistency reliability (Chin, 1998). It should be clarified that we performed a confirmatory factor analysis that was executed as part of the PLS run. More specifically, after running the PLS algorithm we assessed the measurement items loadings of each factor with two criteria to decide if they needed to be included or removed. First, the loading of a measurement item on its corresponding factor should be higher than 0.7 (Lowry \& Gaskin, 2014). Second, all the loadings of the item on their corresponding factor should be an order of magnitude larger than any other cross-loading (Gefen and Straub, 2005). Considering these rules, only three measurement items were dropped from the factor 'partner variety' (see Appendix) while all the other items load cleanly on their intended factor.

To confirm the convergent validity of the first-order reflective variables, we examined the outer loadings of the indicators and the average variance extracted (AVE) as suggested by Hair et al. (2014). Most of the standardized loadings from the PLS model were above 0.6 and statistically significant at $p<0.05$, providing evidence for convergent validity (Chin, 1998). Also, the AVE for all the reflective variables but one exceeded the desired value of 0.50, helping to establish convergent validity (Fornell and Larcker, 1981). We chose to include three items with loadings between 0.40 and 0.60 and the reflective variable with an AVE of 0.44 on the basis that they contributed to the study content validity. Deleting them did not considerably increase the overall composite reliability of the model (Hair et al., 2014).

We also evaluated the discriminant validity of each reflective variable by examining its uniqueness and whether it captured phenomena not described by other variables in the model (Hair et al., 2014). An analysis of the cross-loadings showed that the outer loadings of each variable were greater than all of its loadings on other variables with the exception of one item with a minimal variance of $2.7 \%$ with another item loading. In any case, to assess further discriminant validity, we used the Fornell-Lacker criterion which showed that the square root of the AVE values for each variable was higher than the greater correlation with any other measured variable (Fornell and Larcker, 1981). The correlations between the latent variables used to measure the constructs in the measurement model are shown in Table 1. 
Table 1. Latent variables correlations.

\begin{tabular}{lcccccccccc}
\hline Variable & IRD & INB & OUT & PV & CV & IVP & INNO & EcP & EnP & SoP \\
\hline Internal R\&D (IRD) & 0.84 & & & & & & & & & \\
Inbound (INB) & 0.58 & 0.75 & & & & & & & & \\
Outbound (OUT) & 0.38 & 0.40 & 0.77 & & & & & & & \\
Partner Variety (PV) & 0.48 & 0.57 & 0.60 & 0.66 & & & & & & \\
Content Variety (CV) & 0.55 & 0.57 & 0.64 & 0.53 & 0.81 & & & & & \\
Innovation Phase Variety (IPV) & 0.52 & 0.67 & 0.52 & 0.56 & 0.69 & 0.76 & & & & \\
Innovativeness (INNO) & 0.60 & 0.69 & 0.65 & 0.69 & 0.78 & 0.76 & 0.85 & & & \\
Economic Performance (EcP) & 0.12 & -0.04 & 0.02 & 0.03 & -0.14 & -0.05 & -0.06 & 0.79 & & \\
Environmental Performance (EnP) & 0.45 & 0.67 & 0.42 & 0.59 & 0.62 & 0.76 & 0.76 & 0.04 & 0.86 & \\
Social Performance (SoP) & 0.57 & 0.67 & 0.44 & 0.60 & 0.66 & 0.64 & 0.81 & 0.08 & 0.84 & 0.85 \\
\hline
\end{tabular}

* The square root of the average variance extracted (AVE) is reported along the diagonal.

Finally, the validity of the indicators measuring the FP construct was assessed with other criteria considering that the formative indicators do not need to be necessarily intercorrelated and instead collinearity issues should be considered (Storey and Kahn, 2010). Thus, to assess the collinearity level of the three formative variables, we compared their tolerance values and variance inflation factors (VIF) as suggested by Hair et al. (2014). The analyses showed that their tolerance value was above 0.20 and their VIF values lower than 5, confirming no collinearity problems (Hair et al., 2011). Also, even though not all economic performance indicators were significant, their outer loadings were greater than 0.5 providing evidence to retain all indicators and confirming the pertinence of the whole measurement model.

\subsection{Structural model test}

As previously shown, the assessment of the variable properties has confirmed their reliability and validity and thus it is appropriate to test the proposed hypotheses with the PSL path model. A note of caution here is appropriate: since a single criterion of goodness-of-fit is not common to assess PLS-SEM estimations, non-parametric assessment criteria are usually used. Thus, goodness-of-fit measures like the chi-square $\left(\chi^{2}\right)$ statistic are not pertinent in a PLS-SEM context (Hair et al., 2014). Instead, heuristic criteria based on the model's predictive capacity such as path coefficients significance, $R^{2}$ values, and $f^{2}$ effect size are preferred (Hair et al., 2011, 2014; Lowry and Gaskin, 2014).

Accordingly, we used a bootstrapping method with 500 resamples, which tests if the model path coefficients were statistically significant by estimating standard errors for the estimates (Ringle et al., 2005). These standard errors were then used to calculate the empirical $t$ values which need to be larger than 1.96 for the path coefficients to be significant at a level of 5\% (Chin, 1998). The path coefficients between the hypothesized constructs and within the measured variables in each construct are depicted in Figure 3. The results indicate that the relationships between OIM and INNO $(0.287, t=2.02)$ and OIP and INNO $(0.629, t=4.238)$ are significant $(p<0.05)$ and thus $\mathrm{H} 1$ and $\mathrm{H} 2$ are supported. Similarly, the path coefficient between INNO and FP is significant $(t=24.412, p<0.05)$ providing evidence to support H3. However, it should be recognized that the relation between FP and its dimension of EcP is not significant $(t=0.008, p>0.05)$, which was expected due to several low or negative correlation values with other indicators, as seen in Table 1 . 


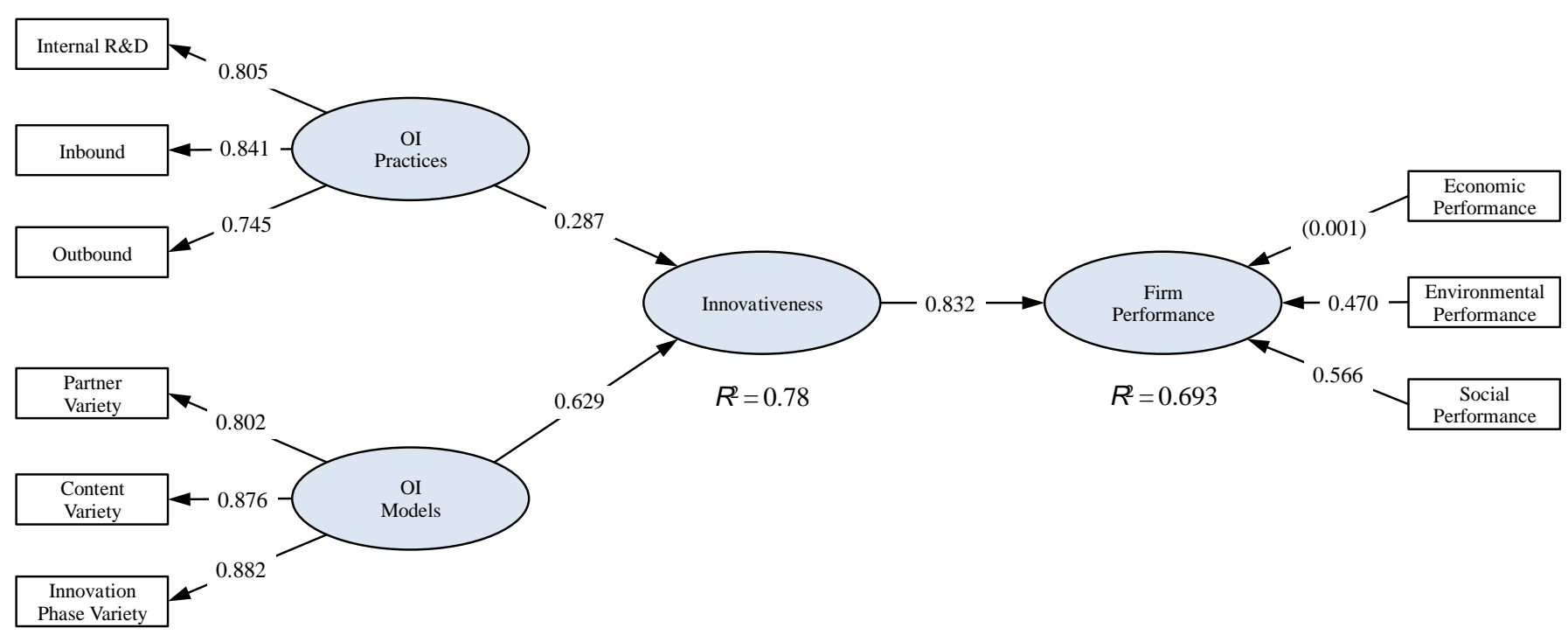

Notes: Path coefficients that are not significant at $p<0.05$ are marked in parentheses.

Figure 3. Path and determination coefficients

In addition, we evaluated the coefficient of determination $\left(R^{2}\right)$, which indicates the model's predictive accuracy and the amount of variance explained by the exogenous constructs. Even though the categorization of $R^{2}$ values varies considerably amongst disciplines (Hair et al., 2014), $R^{2}$ effect sizes of $0.25,0.50$, and 0.75 can be considered respectively as weak, moderate, and substantial (Hair et al., 2011). Considering these criteria, the $R^{2}$ value related to INNO $(0.78)$ can be considered as having a substantial level of predictive accuracy, while the $R^{2}$ value for FP (0.693) indicates a moderate one. Moreover, once the $R^{2}$ values are computed, it is also possible to calculate the $f^{2}$ effect size to assess whether excluding an exogenous construct has a relevant impact on endogenous constructs (Lowry and Gaskin, 2014). A first estimation excluding OIP from the model provided an $f^{2}$ effect size of 0.114 , while a second one excluding OIM showed an $f^{2}$ value of 0.541 . According to the categorization of $f^{2}$ effect sizes, i.e. small 0.02, medium 0.15, and large 0.35 (Cohen, 1992), it is visible that the effect size of OIP on INNO is medium. In contrast, the effect size of OIM on INNO is larger, providing evidence to support H2a.

We also conducted supplementary analyses to identify potential heterogeneity issues. Thus, we used a PLS multigroup analysis (PLS-MGA) to disclose the effect of relevant categorical moderator variables between groups of data (Hair et al., 1998). Considering pairs of groups with a similar size sample, we calculated a PLS-MGA in terms of region (Europe, $n=24$ vs. others, $n=24$ ), firm size (micro and small, $\mathrm{n}=35$ vs. medium $\mathrm{n}=13)$, and firm age $(<15$ years, $\mathrm{n}=23,>15$ years, $\mathrm{n}=25)$. The analyses indicated no significant difference in the effect of region, size or age on the relationships between OIM, OIP, INNO and FP, confirming heterogeneity in the data. Finally, to test the model further, we examined some nonhypothesized relationships. As we expected, the direct relationships between OIP and OIM with FP were nonsignificant. Similarly, we conducted Sobell tests and computed the variance-accounted-for (VAF) measure (see Hair et al., 2014) to examine the mediation of INNO. As anticipated, the results indicated that INNO fully mediates the effect between the studied OI approaches and FP.

\section{Discussion}

\subsection{Theoretical contribution}


In recent years, numerous studies have recognized the evolution towards a contingent view of innovation management that is sensitive to the specific context where the innovation occurs (Aas et al., 2015; Ortt and van der Duin, 2008). Similarly, researchers have emphasized that the adoption, implementation, and success of OI is highly dependent on the context and its factors (Bianchi, Chiaroni, et al., 2011; Huizingh, 2011; Lazzarotti et al., 2011a, 2011b). Consequently, it is valuable to research OI in contexts with particular characteristics, which then could help understand more effectively the specific underlying mechanisms and outcomes of being more or less open (Lazzarotti et al., 2015; Schuster and Brem, 2015). Considering the above, this study has focused on SMMS to portray how specialized SMEs are also adopting and implementing OI to a great extent, allowing them to survive in a highly competitive mature industry (Gerhard et al., 2008). Therefore, the general findings of this study contribute to the shift urged in the OI literature of avoiding potential misleading general prescriptions and instead providing more focused implications for OI research and practice (Tidd, 2014). Aligned to this idea, our study contributes to literature in various ways by exploring the role of openness in terms of practices and models in supporting the innovativeness and performance of SMEs in the automotive industry (Ili et al., 2010; Karlsson and Sköld, 2013; Lazzarotti et al., 2013; De Massis et al., 2012; Schuster and Brem, 2015).

First, the $R^{2}$ value of INNO found in our model confirms the substantial effect that both OI practices and OI models have on predicting the innovation level of specialized SMEs. Accordingly, these findings provide additional evidence for both research streams, stating the relevance of improving SMEs' innovativeness by adopting OI in terms of different practices (Mazzola et al., 2012; Schroll and Mild, 2011; Xiaobao et al., 2013) or with a variety of models (Bengtsson et al., 2015; Bianchi et al., 2011; Lazzarotti and Manzini, 2009; Manzini et al., 2013). It should be noted that the results related to partner variety differ from those of previous studies that found an inverted U-shaped relationship between OI breadth and innovation performance (Chen et al., 2011; Laursen and Salter, 2006; Vahter et al., 2015). Thus, our results contribute to the studies that do not find such curvilinear relationships (Chiang and Hung, 2010; Ebersberger et al., 2012; Enzing et al., 2011; Martini et al., 2012; Michelino et al., 2014), and which are usually justified by the contextual factors of the studied firms. In the case of SMMS, these specialized SMEs may hesitate to change often their typical innovation practices and partners due to their resource constraints, but adopting OI could provide new opportunities for diversifying innovation routes and not harming the overall innovation performance (Ahn et al., 2015).

Moreover, it should be highlighted that there are some sizeable differences in the roles played by some of the variables and the measurement items of each OI construct i.e. OIM and OIP. For instance, even though SMEs perceive investing in economic and human resources to support internal R\&D as important, they put less emphasis on producing intellectual property. Also, in general, INB shows a higher effect in OIP than IRD or OUT practices, suggesting that not all innovation practices have an equally significant effect on SMEs' innovation output (Kim and Park, 2010). In fact, INB practices such as buying technical services, performing technology scouting and training personnel externally were regarded as highly important. Similarly, selling technical or scientific services based on the firm experience were deemed more important than other OUT practices. These results corroborate that SMEs use knowledge search, acquisition, and sourcing activities considerably (Ebersberger et al., 2012; Liao and Barnes, 2015) as well as knowledge-sharing practices (Zanzouri and Francois, 2013) to increase their level of innovativeness (Cheng and Huizingh, 2014; Parida et al., 2012).

Second, the findings not only indicate that OI models have a larger effect than OI practices on INNO, but also similar patterns of unequal effects regarding the variety of the OI models preferred. For example, the 
analyses show that SMMS view having collaborations with different partners as most important but only up to a certain number. While our results may contrast with the idea that the optimal number of external partners for innovation needs to be relatively high (Laursen and Salter, 2006), focusing on few but key partners could also be optimal for SMEs (Corral de Zubielqui et al., 2016). In the case of SMMS these key partners include innovation intermediaries, suppliers, and universities, but surprisingly not customers or trade associations. This finding confirms that while small firms could also use a wide set of innovation linkages, it is particularly important for them to find the most appropriate partners (Vahter et al., 2015). Moreover, the results also indicate that these types of SMEs are more interested in collaborating with external partners, mainly to obtain reliable deliveries, system responsiveness, and supply chain capability primarily during the engineering and manufacturing stages of the innovation process and not during the idea generation or concept phase as other automotive firms emphasize (Gerhard et al., 2008; Schuster and Brem, 2015). Thus, specialized manufacturing SMEs seem to follow similar approaches to medium firms in high-tech industries who focus more on the degree and quality of the external knowledge obtained rather than on the quantity of practices and collaborations (Martini et al., 2012). Therefore, our study not only contributes to the literature on the management of collaborative processes between SMEs and different types of external partners through a variety of mechanisms (Brem et al., 2014; Niehaves and Plattfaut, 2011), but also to the literature on investigating the antecedents, processes and activities of the alliances used by SMEs to improve their level of innovativeness and other outcomes (Jang et al., 2016; Lazzarotti et al., 2015; Sikimic et al., 2016; Zhao, 2014).

Third, this study provides novel insights onto the adoption of OI when considering SMMS as an example of manufacturing SMEs characterized by a particular level of sophistication (Kaulich, 2012) and intentionally choosing a specialization approach. For instance, our results differ from Ihl et al. (2012) who found that high levels of specialization can be detrimental for firms wanting to use more external knowledge sources to improve innovation outcomes. On the contrary, in the case of SMMS, it is likely that without the support of external actors, these firms would not be able to obtain all of the knowledge and resources required to build their one-of-a-kind vehicles, and thus product design would be anymore a strategic choice (Simoni et al., 2014). In this sense, SMMS - like other specialized SMEs - could be using OI practices to obtain new and deep knowledge from other actors with the purpose of improving their radical innovation outcome and simultaneously gaining knowledge to incrementally improve their products (Martini et al., 2012). Our findings provide further evidence of how firms that choose a less diversified strategy are inclined towards OI practices to increase their level of innovativeness (Crema et al., 2014). Consequently, the adoption of OI could be selected as a strategy to diversify the sources of knowledge used by specialized SMEs. From this viewpoint, the diversification is not in their products but in their approaches to innovation, while they remain specialized and retain their (re)sources of competitive advantage (Barney, 1991). This in turn could help SMEs to become more 'sophisticated' by becoming vertically integrated or technology specialists (Padula et al., 2015).

Fourth, the results concerning the influence of OI on INNO and consequently on FP provide some relevant implications for the overall performance of SMEs. To begin with, the significant presence of different practices and models with diverse degrees of adoption suggests that specialized SMEs are able to generate profitable innovations based on complex information complemented by networks or communities to which they or their partners belong (Langner and Seidel, 2014). Our findings also confirm that OIP and OIM have significant relationships with INNO, specifically with indicators related to reducing both new product development costs and time to market. Moreover, because the items used to 
measure innovativeness echo those of Bengtsson et al. (2015), adopting OI models and OI practices could also have significant effects on SMEs' levels of innovation efficiency and novelty. In addition, the results provide evidence on the full mediating role of INNO to increase FP. We recognize that a detailed analysis of each variable of FP does not show a significant effect of INNO, and thus OI, on economic performance. Nevertheless, the results add further evidence to other studies by finding a positive relationship between adopting OI and increasing some environmental indicators in manufacturing SMEs (Cagno et al., 2015; Ramirez-Portilla et al., 2014). Likewise, it is one of the first studies to show the link between adopting OI and some indicators of social performance in SMEs such as adopting an approach to social responsibility or the appropriate management of human resources (Lenz et al., 2016; Podmetina et al., 2013).Thus, even though this study could not confirm a strong effect on economic indicators, the findings suggest that by implementing OI, SMEs could obtain knowledge, resources, and capabilities to achieve sustainability in their innovation and performance (Ketata et al., 2014).

Finally, and considering the above, further studies should attempt to understand better the degree and combination of OI approaches implemented by SMEs which can simultaneously influence the three dimensions of sustainability performance (Prabawani and Barret, 2013). Moreover, even though recent studies have shown the advantage of a substitution effect for some OI practices such as licensing (Bianchi et al., 2014), the simultaneous convergence of other OIP and OIM adopted by SMEs needs to be examined. If the idea of having a complementary effect within specific OI notions instead of a substitutionary one is valid (Ebersberger et al., 2012; Schroll and Mild, 2012), it opens the possibility of aggregating selective OIP and OIM within an SME's strategy (Barge-Gil, 2013; Crema et al., 2014). While adopting several configurations of OI might not have a strong influence on all of the indicators of FP, the adoption of a few specific practices and models might provide better results (Bengtsson et al., 2015). Therefore, a more restricted approach on the complementary effects compared to substitutionary ones of OI models and practices (Sikimic et al., 2016) should also be investigated in the context of specialized manufacturing SMEs.

\subsection{Practical implications}

This study has investigated the implementation of OI by SMMS based on its novelty as a research context but also for its practical relevance, which is rarely highlighted. Historically, several innovations currently adapted to mass volume vehicles built by large carmakers have been created by SMMS (Zapata and Nieuwenhuis, 2010). Therefore, by investigating this context, we attempted to provide managers with a suitable example of how specialized SMEs in mature industries could adopt OI, allowing them to combine exploitative and exploratory approaches (Ebersberger et al., 2012). Likewise, although the case and findings from this study could be primarily relevant for managers in SMEs, large firms and other actors should also find useful insights regarding the potential to collaborate with firms that may even look apparently closed because of their specialization strategy. Moreover, through the case of SMMS, this study shows practitioners how even in mature traditional industries, SMEs can play the important role of explorers of markets or as technical specialists (Chesbrough, 2010) allowing them to generate innovation with a great potential for diffusion.

Additionally, we believe that this paper shows policy makers and managers of manufacturing SMEs novel insights about the benefits of adopting OI practices and OI models. More precisely, our study proposes that adopting and implementing OI can have an important influence on a manufacturing firm's environmental and social performance, which is of considerable importance given the current policies 
encouraging sustainability in this sector (De Backer, 2015; European Commission, 2010; OECD, 2009). Moreover, we expect that practitioners from SMEs in mature industries might take our results as empirical evidence that adopting OI could provide them with a clear opportunity to increase their level of innovativeness but also to become sustainable, resource-efficient, and more competitive (European Commission, 2010). It is our hope that due to our findings more managers in SMEs might realize the potential to acquire special expertise through collaborative approaches, which could later be transformed into operational skills and even into best practices in their industry (Zanzouri and Francois, 2013).

Lastly, and from a critical viewpoint, the overall findings of this study signal that, as with several management concepts, the effectiveness of OI may not have optimal effects in any situation (Huizingh, 2011). Therefore, managers should bear in mind that even though the share of firms adopting OI has greatly increased in recent last years, they have adopted it with different degrees of intensity (Cricelli et al., 2015). As shown in our study, SMEs could adopt OI to compete more effectively with large firms through collaboration or even co-opetition (Zhao, 2014), but not all partners might be appropriate to implement these approaches. For instance, many SMEs choose to be more open with specific practices and collaborate with non-competing partners who do not threaten their business (Ahn et al., 2015). Thus, on the one hand, it seems that several SMEs could adopt OI to be more innovative and have better performance without posing much risk to their specialization strategy. On the other hand, an SME could also become more diversified due to OI. In this case, practitioners and policy makers may find beneficial a complementarity between specialized, diversity, and integrated firms in an specific industry, creating additional value for the whole ecosystem (Funk and Luo, 2015).

\subsection{Limitations and future research}

As in all research, this study is subject to particular limitations that could help identify insights and directions for future research. The first limitation concerns some drawbacks related to the study sample such as size, population uncertainty, and bias in the response rate due to language barriers. For instance, considering that the exact population of SMEs focusing on making supercars is unknown, the nature of the sample might not be perfectly representative of the whole industry. However, the research context was deemed to be innovative enough to examine the innovativeness of SMEs specialized in designing and making one-of-a-kind vehicles, as few studies have remarked (Langner and Seidel, 2014). In this regards, even though the study focused in one single industry, some of the findings could be extrapolated to continue studying OI in other traditional industries. For example, similar studies could be conducted to understand the influence of adopting OI to innovate in one-off projects or luxury products (Brun and Castelli, 2013; Ponticelli et al., 2013), such as custom-built yachts or watches, but also in design-driven firms where the design of unique products is used as a strategic weapon (Simoni et al., 2014).

A second limitation relates to the cross-sectional approach of the survey, which was not originally viewed as a main drawback. However, during the search for SMMS for almost two years, it was noticed that several of them had gone bankrupt and new players were constantly emerging. Thus, even though responses from some new entrants were obtained, the survey did not manage to collect responses from firms that had become non-operational during the survey period (e.g. Yes! Motors or Gumpert). This situation provides the opportunity for further study if some specialized SMEs disappear even though they are implementing OI successfully or if there are some negative effects of openness when developing new products such as worse timing to market, slower product development or more costly products (Knudsen 
\& Mortensen, 2011). Understanding these other effects could provide more insights on whether it is more convenient to adopt OI or remain as closed as possible (Manzini et al., 2016). Similarly, our study did not find a positive relationship between innovativeness and economic performance. However, the findings related to environmental and social performance provide additional insights about the overall competitiveness level of the SMEs. Thus, future longitudinal studies could explore whether an SME has better opportunities to improve its economic performance if it can develop a robust level of the other two, with the purpose of improving its overall sustainability performance (Bos-Brouwers, 2010).

Third, while our study was able to find significant relationships between relevant OI variables showing the potential of openness, its scope did not allow focusing on some of the actual challenges related to OI execution (Gwynne, 2007). A good example of these challenges is that OI practices do not happen alone but there should be a person or group of persons conducting them. In fact, recent studies are stressing the managerial roles that appear to be crucial for organizing OI (Ollila and Yström, 2016), and in general challenges of human resource management when adopting OI need to be further studied (Lenz et al., 2016; Podmetina et al., 2013). Thus, we believe promising to investigate the dynamics and implications for managerial choice and agency when implementing OI since lacking them could hinder OI collaborations (Tushman et al., 2012). Considering the above, we acknowledge that our study did not discuss the implications of having or lacking a full-time innovation manager in the studied SMMS. Thus, future research should focus on understanding if having experienced managers in OI or other collaborative innovation approaches would be enough for a specialized SME to successfully implement OI. For instance, in principle an SMMS could obtain valuable ideas through competitions or online communities (Langner and Seidel, 2014); however, creating a community of users or crowdsourcing competitions could fail not because of an agency problem but due to the lack of user/adopter interest (Dahlander \& Magnusson, 2005) or even personality dispositions (West \& Lakhani, 2008).

The fourth and last shortcoming concerns the selection of variables used for this study. For example, for good or for bad, OI is considered as a multidimensional construct (De Backer and Cervantes, 2008). Therefore, although OI was measured with numerous items related to models and practices, other dimensions of OI depicted in the literature were not considered. Similarly, another area for future research related to this study would be to complement the framework with other relevant variables mediating and moderating the relationships between OI and firm performance in SMEs. These could range from more recognized variables in OI literature such as absorptive capacity (Corral de Zubielqui et al., 2016; Spithoven et al., 2010) to variables from other disciplines which are also key to innovation and value creation such as entrepreneurial orientation (Cheng and Huizingh, 2014; Hung and Chiang, 2010) . In line with this idea, additional empirical investigation is required to explore the influence of contextual factors in the implementation of OI by SMEs in underexplored industries. It therefore seems that studies focusing on investigating the implications of internal and external contingency variables on OI (Ahn et al., 2015; Lazzarotti et al., 2015; Michelino et al., 2014; Schuster and Brem, 2015) will continue to be an interesting and promising line of enquiry for further research.

\section{References}

Aas, T.H., Breunig, K.J., Hydle, K.M. and Pedersen, P.E. (2015), "Innovation management practices in production-intensive service firms”, International Journal of Innovation Management, Vol. 19 No. 05, p. 1550055. 
Ahn, J.M., Minshall, T. and Mortara, L. (2015), “Open innovation: a new classification and its impact on firm performance in innovative SMEs", Journal of Innovation Management, Vol. 3 No. 2, pp. 33-54.

Aloini, D. and Martini, A. (2013), "Exploring the exploratory search for innovation: A structural equation modelling test for practices and performance”, International Journal of Technology Management, Vol. 61 No. 1, pp. 23-46.

Aloini, D., Martini, A. and Pellegrini, L. (2011), “A structural equation model for continuous improvement: a test for capabilities, tools and performance”, Production Planning \& Control, Vol. 22 No. 7, pp. 628-648.

Azadegan, A. and Dooley, K.J. (2010), "Supplier innovativeness, organizational learning styles and manufacturer performance: An empirical assessment”, Journal of Operations Management, Vol. 28 No. 6, pp. 488-505.

De Backer, K. (2015), The next production revolution, Paris.

De Backer, K. and Cervantes, M. (2008), Open Innovation in Global Networks, Paris: OECD Publishing.

Barge-Gil, A. (2013), “Open Strategies and Innovation Performance”, Industry \& Innovation, Vol. 20 No. 7, pp. 585-610.

Barney, J. (1991), "Firm Resources and Sustained Competitive Advantage”, Journal of Management, Vol. 17 No. 1, p. 99/120.

Bengtsson, L., Lakemond, N., Lazzarotti, V., Manzini, R., Pellegrini, L. and Tell, F. (2015), “Open to a Select Few? Matching Partners and Knowledge Content for Open Innovation Performance”, Creativity and Innovation Management, Vol. 24 No. 1, pp. 72-86.

Bianchi, M., Campodall'Orto, S., Frattini, F. and Vercesi, P. (2010), "Enabling open innovation in small- and medium-sized enterprises: how to find alternative applications for your technologies”, R\&D Management, Vol. 40 No. 4, pp. 414-431.

Bianchi, M., Cavaliere, A., Chiaroni, D., Frattini, F. and Chiesa, V. (2011), "Organisational modes for Open Innovation in the bio-pharmaceutical industry: An exploratory analysis”, Technovation, Elsevier, Vol. 31 No. 1, pp. $22-33$.

Bianchi, M., Chiaroni, D., Chiesa, V. and Frattini, F. (2011), “Organizing for external technology commercialization: evidence from a multiple case study in the pharmaceutical industry", $R \& D$ Management, Vol. 41 No. 2, pp. 120-137.

Bianchi, M., Frattini, F., Lejarraga, J. and Di Minin, A. (2014), “Technology Exploitation Paths: Combining Technological and Complementary Resources in New Product Development and Licensing”, Journal of Product Innovation Management, Vol. 31 No. S1, pp. 146-169.

Boer, H., Kuhn, J. and Gertsen, F. (2006), Continuous Innovation Managing Dualities through Co-ordination, WP $2006-01$.

Bos-Brouwers, H.E.J. (2010), "Corporate sustainability and innovation in SMEs: Evidence of themes and activities in practice", Business Strategy and the Environment, Vol. 19 No. 7, pp. 417-435.

Braun, A. (2015), "Linking business model and open innovation - success and failure of collaborations", International Journal of Entrepreneurship and Innovation Management, Vol. 19 No. 1/2, p. 2015.

Brem, A., Gerhard, D.A. and Voigt, K.-I. (2014), "Strategic Technological Sourcing Decisions in the Context of Timing and Market Strategies: An Empirical Analysis.”, International Journal of Innovation \& Technology Management, Vol. 11 No. 3, p. 1450016.

Breschi, S. and Malerba, F. (1999), Diversification and specialisation in innovative activities: an analysis of patenting activity of electronic firms, Milan, Italy.

Brun, A. and Castelli, C. (2013), "The nature of luxury: a consumer perspective", International Journal of Retail \& Distribution Management, Vol. 41 No. 11/12, pp. 823-847.

Brunswicker, S. and Vanhaverbeke, W. (2014), Open Innovation in Small and Medium-Sized Enterprises (SMEs): External Knowledge Sourcing Strategies and Internal Organizational Facilitators, Journal of Small Business Management, Vol. 8, pp. 1-23.

Cagno, E., Ramirez-Portilla, A. and Trianni, A. (2015), "Linking energy efficiency and innovation practices: Empirical evidence from the foundry sector”, Energy Policy, Vol. 83, pp. 240-256.

Caird, S., Hallett, S. and Potter, S. (2013), “The Open2-Innova8ion Tool-A software tool for rating organisational innovation performance", Technovation, Elsevier, Vol. 33 No. 10-11, pp. 381-385.

Cheetham, C. (2006), Supercars: The World's Most Exotic Sports Cars, (MotorBooks,Ed.).

Chen, J., Chen, Y. and Vanhawerbeke, W. (2011), "The influence of scope, depth and orientation of external technology sources on the innovative performance of Chinese firms", Technovation, Vol. 51 No. 8, pp. 562-573.

Cheng, C.C.J. and Huizingh, E.K.R.E. (2014), "When is open innovation beneficial? The role of strategic orientation", Journal of Product Innovation Management, Vol. 31 No. 6, pp. 1235-1253.

Chesbrough, H. (2003), Open innovation: The new imperative for creating and profiting from technology, Harvard Business Press, Boston.

Chesbrough, H. (2006), “Open innovation: A new paradigm for understanding industrial innovation”, in Chesbrough, H., W.Vanhaverbeke, W. and West, J. (Eds.), Open innovation: Researching a new paradigm, Oxford University Press, Oxford, pp. 1-12.

Chesbrough, H. (2010), “How Smaller Companies Can Benefit from Open Innovation”, Economy, Culture \& History Japan 
Spotlight, Vol. 29 No. 1, pp. 13-15.

Chesbrough, H. and Bogers, M. (2014), "Explicating open innovation: clarifying an emerging paradigm for understanding innovation", in Chesbrough, H., Vanhaverbeke, W. and West, J. (Eds.), New Frontiers in Open Innovation, University Press, Oxford, p. 368.

Chesbrough, H. and Crowther, A. (2006), "Beyond high tech: early adopters of open innovation in other industries.”, $R \& D$ Management, Vol. 36 No. 3, pp. 229-236.

Chesbrough, H., Vanhaverbeke, W. and West, J. (2006), Open Innovation: Researching a New Paradigm, Oxford University Press, Oxford.

Chiang, Y.H. and Hung, K.P. (2010), "Exploring open search strategies and perceived innovation performance from the perspective of inter-organizational knowledge flows", R\&D Management, Vol. 40 No. 3, pp. 292-329.

Chin, W.W. (1998), “The Partial Least Squares Approach to Structural Equation Modeling”, in Marcoulides, G.A. (Ed.),Modern Methods for Business Research, Lawrence Erlbaum, Hillsdale, NJ, pp. 295-335.

Cohen, J.A. (1992), “A power primer”, Psychological bulletin, Vol. 112 No. 1, pp. 155-159.

Corral de Zubielqui, G., Jones, J. and Lester, L. (2016), "Knowledge inflows from market- and science-based actors, absorptive capacity, innovation and performance: A study of SMEs", International Journal of Innovation Management, Vol. 20 No. 6, p. 1650055.

Crema, M., Verbano, C. and Venturini, K. (2014), "Linking strategy with open innovation and performance in SMEs", Measuring Business Excellence, Vol. 18 No. 2, pp. 14-27.

Cricelli, L., Greco, M. and Grimaldi, M. (2015), “Assessing the Open Innovation Trends By Means of the Eurostat Community Innovation Survey”, International Journal of Innovation Management, Vol. 20 No. 3, p. 1650039.

Dahlander, L. and Gann, D.M. (2010), “How open is innovation?”, Research Policy, Elsevier B.V., Vol. 39 No. 6, pp. 699709.

Dahlander, L. and Magnusson, M.G. (2005), "Relationships between open source software companies and communities: Observations from Nordic firms", Research Policy, Vol. 34 No. 4, pp. 481-493.

Dai, L., Maksimov, V., Gilbert, B.A. and Fernhaber, S. a. (2014), "Entrepreneurial orientation and international scope: The differential roles of innovativeness, proactiveness, and risk-taking”, Journal of Business Venturing, Elsevier Inc., Vol. 29 No. 4, pp. 511-524.

van deVrande, V., De Jong, J., Vanhaverbeke, W. and de Rochemont, M. (2009), “Open innovation in SMEs: trends, motives and management challenges”, Technovation, Vol. 29 No. 6-7, pp. 423-437.

Ebersberger, B., Bloch, C., Herstad, S.J. and van de Velde, E. (2012), “Open Innovation Practices and their Effect on Innovation Performance", International Journal of Innovation and Technology Management, Vol. 9 No. 6, pp. 1-22.

Enzing, C.M., Pascucci, S., Janszen, F.H.A. and Omta, O.S.W.F. (2011), "Role of open innovation in the short- and long-term market success of new products: Evidence from the Dutch food and beverages industry", Journal on Chain and Network Science, Vol. 11 No. 3, pp. 235-250.

European Commission. (2010), Europe 2020: a strategy for smart, sustainable and inclusive growth: communication from the Commission, Brussels.

Eurostat. (2013), “Community Innovation Survey (CIS)”, Community Innovation Survey (CIS) - Description of dataset, available at: http://epp.eurostat.ec.europa.eu/portal/page/portal/microdata/cis.

Fink, A. (2003), The survey handbook, Sage Publications Ltd, London.

Fornell, C. and Larcker., F. (1981), "Evaluating structural equation models with unobservable variables and measurement errors", Journal of Marketing Research, Vol. 18 No. 1, pp. 39-50.

Forza, C. (2002), "Survey Research in Operations Management: A Process-Based Perspective”, International Journal of Operations and Production Management, Vol. 22 No. 2, pp. 152-194.

Funk, J.L. and Luo, J. (2015), “Open standards, vertical disintegration and entrepreneurial opportunities: How verticallyspecialized firms entered the U.S. semiconductor industry”, Technovation, Vol. 45-46, pp. 52-62.

Gambardella, A. and Panico, C. (2014), "On the management of open innovation”, Research Policy, Elsevier B.V., pp. 1-11.

Garcia, R. and Calantone, R. (2002), “A critical look at technological innovation typology and innovativeness terminology: A literature review", Journal of Product Innovation Management.

Gassmann, O. and Enkel, E. (2004), "Towards a Theory of Open Innovation : Three Core Process Archetypes", $R \& D$ Management Conference (RADMA), Lisbon, Portugal, pp. 1-18.

Gefen, D. and Straub, D. (2005), “A practical guide to factorial validity using PLS-Graph: Tutorial and annotated example”, Communications of the Association for Information systems, Vol. 16 No. 1, pp. 91-109.

Gerhard, D., Brem, A. and Voigt, K.I. (2008), "Product development in the automotive industry: crucial success drivers for technological innovations”, International Journal of Technology Marketing, Vol. 3 No. 3, pp. 203-222. 
Global Reporting Initiative. (2006), Sustainability reporting guidelines on economic, environmental, and social performance, Amsterdam, Amsterdam.

Grundström, C., Sjöström, R. and Öhrwall Rönnbäck, A. (2013), "Manufacturing SMEs and Open Innovation - findings from Sweden”, The 6th ISPIM Innovation Symposium, Melbourne, Australia, pp. 1-18.

Gwynne, P. (2007), “Open Innovation’s Promise and Perils.”, Research Technology Management.

Hair, J.F., Anderson, R.., Tatham, R.L. and Black, W.C. (1998), Multivariate Data Analysis, Prentice Hall, Upper Saddle River, NJ, 5thed.

Hair, J.F., Hult, G.T. oma. M., Ringle, C.M. and Sarstedt, M. (2014), A Primer on Partial Least Squares Structural Equation Modeling (PLS-SEM), Sage Publications, Thousand Oaks, CA.

Hair, J.F., Ringle, C.M. and Sarstedt, M. (2011), "PLS-SEM: Indeed a silver bullet", Journal of Marketing Theory and Practice, Vol. 19 No. 2, pp. 139-151.

Handrich, M., Handrich, F. and Heidenreich, S. (2015), "Firm Innovativeness - The sufficient condition for business success? Examining antecedents of firm innovativeness and how it affects business success", International Journal of Innovation Management, Vol. 19 No. 5, p. 1550053.

Hansen, E.G., Grosse-Dunker, F. and Reichwald, R. (2009), "Sustainability innovation cube-a framework to evaluate sustainability-oriented innovations”, International Journal of Innovation Management, Vol. 13 No. 04, pp. 683-713.

He, Z.L. and Wong, P.K. (2004), "Exploration vs. Exploitation: An Empirical Test of the Ambidexterity Hypothesis", Organization Science, Vol. 15 No. 4, pp. 481-494.

Huizingh, E. (2011), “Open innovation: State of the art and future perspectives”, Technovation, Elsevier, Vol. 31 No. 1, pp. 29.

Hung, K.-P. and Chiang, Y.-H. (2010), “Open innovation proclivity, entrepreneurial orientation, and perceived firm performance”, International Journal of Technology Management, Vol. 52 No. 3/4, pp. 257-274.

Idrissia, M.O., Amaraa, N. and Landrya, R. (2012), "SMEs' Degree of Openness: The Case of Manufacturing Industries", Journal of Technology Management \& Innovation, Vol. 7 No. 1, pp. 186-210.

Ihl, C., Piller, F. and Wagner, P. (2012), Organizing for Open Innovation - Aligning Internal Structure and External Knowledge Sourcing, available at: Available at SSRN: http://ssrn.com/abstract=2164766.

Ili, S., Albers, A. and Miller, S. (2010), “Open innovation in the automotive industry”, R\&D Management, Vol. 40 No. 3 , pp. $246-255$.

Jang, H., Lee, K. and Yoon, B. (2016), "Development of an Open Innovation Model for R\&D Collaboration between Large Firms and Small-Medium Enterprises (SMEs) in Manufacturing Industries”, International Journal of Innovation Management, Vol. 00 No. 00, doi:10.1142/S1363919617500025.

Karlsson, C. and Sköld, M. (2013), "Forms of innovation openness in global automotive groups", International Journal of Automotive Technology and Management, Vol. 13 No. 1, pp. 1-17.

Kaulich, F. (2012), Diversification vs. specialization as alternative strategies for economic development: Can we settle a debate by looking at the empirical evidence?, 03/2012, Vienna.

Ketata, I., Sofka, W. and Grimpe, C. (2014), “The role of internal capabilities and firms' environment for sustainable innovation: evidence for Germany”, R\&D Management, Vol. 45 No. 1, pp. 60-75.

Kim, H. and Park, Y. (2010), "The effects of open innovation activity on performance of SMEs: the case of Korea", International Journal of Technology Management, Vol. 52 No. 3, pp. 236-256.

Kolk, A. and Püümann, K. (2008), "Co-development of open innovation strategy and dynamic capabilities as a source of corporate growth", Journal of Economic Literature, Vol. 173, pp. 73-83.

Lai, H.-C., Chiu, Y.-C. and Liaw, Y.-C. (2010), “Can external corporate venturing broaden firm's technological scope? The role of complementary assets", Journal of Engineering and Technology Management, Vol. 27 No. 3-4, pp. $183-196$.

Langner, B. and Seidel, V.P. (2014), "Sustaining the Flow of External Ideas: The Role of Dual Social Identity across Communities and Organizations”, Journal of Product Innovation Management, In Press, Vol. 32 No. 4, pp. $522-538$.

Laursen, K. and Salter, A. (2006), "Open for innovation: the role of openness in explaining innovation performance among U.K. manufacturing firms”, Strategic management Journal, Vol. 27 No. 2, pp. 131-150.

Lazzarotti, V. and Manzini, R. (2009), "Different Modes of Open Innovation: a Theoretical Framework and an Empirical Study”, International Journal of Innovation Management, Vol. 13 No. 04, pp. 615-636.

Lazzarotti, V., Manzini, R. and Pellegrini, L. (2010), “Open innovation models adopted in practice: an extensive study in Italy”, Measuring Business Excellence, Vol. 14 No. 4, pp. 11-23.

Lazzarotti, V., Manzini, R. and Pellegrini, L. (2011a), "Firm-specific factors and the openness degree: a survey of Italian firms", European Journal of Innovation Management, Vol. 14 No. 4, pp. 412-434.

Lazzarotti, V., Manzini, R. and Pellegrini, L. (2011b), "Contextual factors and open innovation: are there contradictory or yet 
little investigated propositions?", International Journal of Innovation and Regional Development, Vol. 3 No. 5, pp. 486514.

Lazzarotti, V., Manzini, R. and Pellegrini, L. (2015), “Is your open-innovation successful? The mediating role of a firm’s organizational and social context”, The International Journal of Human Resource Management, Vol. 26 No. 19, pp. 2453-2485.

Lazzarotti, V., Manzini, R., Pellegrini, L. and Pizzurno, E. (2013), “Open Innovation in the automotive industry: Why and How? Evidence from a multiple case study”, International Journal of Technology Intelligence and Planning, Vol. 9 No. 1, pp. 37-56.

Lenz, S., Pinhanez, M., Urtubey de Césaris, L.E. and Jacobs, C. (2016), “Open Innovation and the Challenges of Human Resource Management”, International Journal of Innovation Management, Vol. 20 No. 07, p. 1650063.

Liao, Y. and Barnes, J. (2015), "Knowledge acquisition and product innovation flexibility in SMEs", Business Process Management Journal, Vol. 21 No. 6, pp. 1257 - 1278.

Lichtenthaler, U. (2008), "Open innovation in practice: an analysis of strategic approaches to technology transactions", IEEE Transactions on Engineering Management, Vol. 55 No. 1, pp. 148-157.

Lichtenthaler, U. (2009), "Outbound open innovation and its effect on firm performance: examining environmental influences.", R\&D Management, Vol. 39 No. 4, pp. 317-330.

Lowry, P.B. and Gaskin, J. (2014), "Partial least squares (PLS) structural equation modeling (SEM) for building and testing behavioral causal theory: When to choose it and how to use it", IEEE Transactions on Professional Communication, Vol. 57 No. 2, pp. 123-146.

Manzini, R., Lazzarotti, V. and Pellegrini, L. (2016), "How to Remain as Closed as Possible in the Open Innovation Era: The Case of Lindt and Sprüngli”, Long Range Planning, Vol. 00 No. 00, doi:10.1016/j.lrp.2015.12.011.

Manzini, R., Lazzarotti, V., Pellegrini, L., Bengtsson, L., Lakemond, N., Tell, F., Öhrwall Rönnbäck, A., et al. (2013), “Are We Actually in the Open Innovation Era? Current Practices of European Manufacturing Companies", 14th International Continuous Innovation Network (CINet) Conference “Business Development and Co-Creation”, Nijmegen, Netherlands, pp. 592-614.

March, J. (1991), "Exploration and exploitation in organizational learning”, Organization Science, Vol. 2 No. 1, pp. $71-87$.

Martini, A., Aloini, D. and Neirotti, P. (2012), "Degree of Openness and Performance in the Search for Innovation", International Journal of Engineering Business Management, Vol. 4 No. 37, pp. 1-15.

De Massis, A., Lazzarotti, V., Pizzurno, E. and Salzillo, E. (2012), “Open Innovation in the Automotive Industry: A Multiple Case-Study", in Sun, H. (Ed.),Management of Technological Innovation in Developing and Developed Countries, InTech, Rijeka, Cro, pp. 217-235.

May, G., Taisch, M. and Kerga, E. (2012), “Assessment of sustainable practices in new product development”, Advances in Production Management Systems. Value Networks: Innovation, Technologies, and Management, Springer Berlin Heidelberg, pp. 437-447.

Mazzola, E., Bruccoleri, M. and Perrone, G. (2012), “The effect of inbound, outbound and coupled innovation on performance", International Journal of Innovation Management, Vol. 16 No. 6, p. 27.

Michelino, F., Caputo, M., Cammarano, A. and Lamberti, E. (2014), "Inbound and Outbound Open Innovation: Organization and Performances", Journal of Technology Management \& Innovation, Vol. 9 No. 3, pp. 65-82.

Michelino, F., Lamberti, E., Cammarano, A. and Caputo, M. (2015), “Open models for innovation: an accounting-based perspective”, International Journal of Technology Management, Vol. 68 No. 1/2, pp. 99-121.

Morris, E. (2004), "Sampling from small populations", University of Regina, available at: http://uregina.ca/ morrisev/Sociology/Sampling from small populations.htm (accessed 30 April 2015).

Mortensen, P.S. and Bloch, C.W. (2005), Oslo Manual: Guidelines for collecting and interpreting innovation data, (Organisation for Economic Co-operation and Development,Ed.), OECD publishing, Paris, 3rded.

Niehaves, B. (2010), "Open process innovation: The impact of personnel resource scarcity on the involvement of customers and consultants in public sector BPM”, Business Process Management Journal, Vol. 16 No. 3, pp. 377 - 393.

Niehaves, B. and Plattfaut, R. (2011), “Collaborative business process management: status quo and quo vadis”, Business Process Management Journal, Vol. 17 No. 3, pp. 384-402.

OECD. (2009), Sustainable manufacturing and eco-innovation: First steps in building a common analytical framework, Paris.

Oh, J. and Rhee, S.K. (2010), "Influences of supplier capabilities and collaboration in new car development on competitive advantage of carmakers", Management Decision, Vol. 48 No. 5, pp. 756 - 774.

Ollila, S. and Yström, A. (2016), “An investigation into the roles of open innovation collaboration managers”, $R \& D$ Management, Vol. 00 No. 00, doi:10.1111/radm.12197.

Ortt, J.R. and van der Duin, P.A. (2008), “The evolution of innovation management towards contextual innovation”, European 
Journal of Innovation Management, Vol. 11 No. 4, pp. 522-538.

Padula, G., Novelli, E. and Conti, R. (2015), "SMEs inventive performance and profitability in the markets for technology", Technovation, Vol. 41-42 No. July-August, pp. 38-50.

Parida, V., Larsson, T., Isaksson, 0. and Oghazi, P. (2011), “Towards open innovation practices in aerospace industry: challenges and opportunities”, 3rd International Conference on Research into Design, ICoRD’11, Bangalore, India.

Parida, V., Westerberg, M. and Frishammar, J. (2012), "Inbound Open Innovation Activities in High-Tech SMEs: The Impact on Innovation Performance”, Journal of Small Business Management, Vol. 50 No. 2, pp. 283-309.

Penrose, E.T. (1959), The Theory of the Growth of the Firm., Blackwell, Oxford.

Podmetina, D., Volchek, D., Dąbrowska, J. and Fiegenbaum, I. (2013), "Human Resources Practices and Open Innovation”, International Journal of Innovation Management, Vol. 17 No. 6.

Podsakoff, P.M., MacKenzie, S.B., Lee, J.Y. and Podsakoff, N.P. (2003), "Common method biases in behavioral research: a critical review of the literature and recommended remedies”, Journal of Applied Psychology, Vol. 88 No. 5, pp. 879903.

Ponticelli, S., Mininno, V., Dulmin, R. and Aloini, D. (2013), "Supply chain implications for one-off luxury products: cases from the yacht industry", International Journal of Retail \& Distribution Management, Vol. 41 No. 11, pp. 1008-1029.

Prabawani, B. and Barret, R. (2013), "Measuring SMEs' Sustainability: A Literature Review and Agenda for Research”, International Journal of Management and Sustainability, Vol. 2 No. 12, pp. 193-207.

Ramirez-Portilla, A., Cagno, E. and Brown, T. (2014), “Open Innovation Practices in SMEs: The case of the Mexican supercar VUHL”, The IV Symposium CONACyT fellows in Europe, Strasbourg, France, p. 11.

Ramirez-Portilla, A., Cagno, E. and Trianni, A. (2014), "Is Innovation an enabler of Energy Efficiency? An exploratory study of the foundry sector", Energy Procedia, Vol. 61, pp. 1191-1195.

Randhawa, K., Wilden, R. and Hohberger, J. (2016), “A Bibliometric Review of Open Innovation: Setting a Research Agenda”, Journal of Product Innovation Management, Vol. 00 No. 00, doi:10.1111/jpim.12312.

Ringle, C.M., Wende, S. and Will, A. (2005), "SmartPLS 2.0”, Hamburg, available at: www.smartpls.de.

Rumelt, R.P. (1982), "Diversification Strategy and Profitability”, Strategic Management Journal, Vol. 3 No. 4, pp. $359-369$.

Rumelt, R.P., Schendel, D.E. and Teece, D.J. (1994), Fundamental issues in strategy: A Research Agenda, Harvard Business School Press, Boston, MA.

Salmelin, B. (Ed.). (2013), Open Innovation 2.0 Yearbook 2013, Luxembourg Publication Office of the European Union, Luxemburg.

Schroll, A. and Mild, A. (2011), "Open innovation modes and the role of internal R\&D: An empirical study on open innovation adoption in Europe”, European Journal of Innovation Management, Vol. 14 No. 4, pp. 475-495.

Schroll, A. and Mild, A. (2012), "A critical review of empirical research on open innovation adoption", Journal für Betriebswirtschaft, Vol. 62 No. 2, pp. 85-118.

Schuster, G. and Brem, A. (2015), "How to benefit from open innovation? An empirical investigation of open innovation, external partnerships and firm capabilities in the automotive industry”, International Journal of Technology Management, Vol. 69 No. 1, pp. 54-76.

Sierzchula, W., Bakker, S., Maat, K. and Wee, B. Van. (2015), "Alliance Formation in the Automobile Sector during an Era of Ferment”, Creativity and Innovation Management, Vol. 24 No. 1, pp. 109-122.

Sikimic, U., Chiesa, V., Frattini, F. and Scalera, V.G. (2016), "Investigating the Influence of Technology Inflows on Technology Outflows in Open Innovation Processes: A Longitudinal Analysis”, Journal of Product Innovation Management, Vol. 00 No. 00, doi:10.1111/jpim.12319.

Simoni, M., Cautela, C. and Zurlo, F. (2014), "Product design strategies in technological shifts: An explorative study of Italian design-driven companies", Technovation, Elsevier, Vol. 34 No. 11, pp. 702-715.

Smith, A., Voß, J.-P. and Grin, J. (2010), "Innovation studies and sustainability transitions: The allure of the multi-level perspective and its challenges", Research Policy, Vol. 39 No. 4, pp. 435-448.

Spithoven, A., Clarysse, B. and Knockaert, M. (2010), "Building absorptive capacity to organize inbound open innovation in traditional industries", Technovation, Vol. 30 No. 1, pp. 130-141.

Storey, C. and Kahn, K.B. (2010), “The Role of Knowledge Management Strategies and Task Knowledge in Stimulating Service Innovation", Journal of Service Research, Vol. 13 No. 4, pp. 397-410.

Teece, D.J. (1986), "Profiting from technological innovation: implications for integration collaboration, licensing and public policy”, Research Policy, Vol. 15, pp. 285-305.

Teece, D.J. (2007), "Explicating Dynamic Capabilities: The Nature and Microfoundations of (Sustainable) Enterprise Performance”, Strategic Management Journal, Vol. 28 No. 13, pp. 1319-1350.

Teece, D.J., Pisano, G. and Shuen, A. (1997), "Dynamic capabilities and strategic management”, Strategic Management 
Journal, Vol. 18 No. 7, pp. 509-533.

Tidd, J. (2014), “Introduction: Why We Need a Tighter Theory and More Critical Research on Open Innovation”, in Tidd, J. (Ed.), Open Innovation Research, Management and Practice, World Scientific, Hackensack, NJ.

Tushman, M., Lakhani, K.R. and Lifshitz-Assaf, H. (2012), “Open Innovation and Organization Design”, Journal of Organization Design, Vol. 1 No. 1, pp. 24-27.

Vahter, P., Love, J.H. and Roper, S. (2015), “Openness and Innovation Performance: Are Small Firms Different?”, Industry and Innovation, Vol. 21 No. 7-8, pp. 553-573.

Vanhaverbeke, W. and Cloodt, M. (2014), "Theories of the firm and open innovation”, in Chesbrough, H., Vanhaverbeke, W. and West, J. (Eds.),New Frontiers in Open Innovation, Oxford University Press, Oxford, UK, pp. 256-278.

Verbano, C., Crema, M. and Venturini, K. (2013), “The Identification and Characterization of Open Innovation Profiles in Italian Small and Medium-sized Enterprises”, Journal of Small Business Management, Vol. 53 No. 4, pp. $1052-1075$.

Verheugen, G. (2003), "The new SME definition: User guide and model declaration", Official Journal of the European Union, p. 51.

Veugelers, R. (1997), “Internal R\&D expenditures and external technology sourcing”, Research Policy, Vol. 26 No. 3, pp. 303-315.

Vij, S. and Bedi, H.S. (2015), "Effect of organisational and environmental factors on innovativeness and business performance relationship", International Journal of Innovation Management, Vol. 20 No. 3, p. 1650037.

van de Vrande, V., de Jong, J.P.J., Vanhaverbeke, W. and de Rochemont, M. (2009), “Open innovation in SMEs: Trends, motives and management challenges”, Technovation, Vol. 29 No. 6-7, pp. 423-437.

West, J. and Bogers, M. (2013), “Leveraging External Sources of Innovation: A Review of Research on Open Innovation”, Journal of Product Innovation Management, Vol. 31 No. 4, pp. 1-18.

West, J. and Gallagher, S. (2006), "Challenges of Open Innovation: The Paradox of Firm Investment in Open Source Software”, R\&D Management, Vol. 36 No. 3, pp. 319-331.

West, J. and Lakhani, K.R. (2008), "Getting Clear About Communities in Open Innovation”, Industry \& Innovation, Vol. 15 No. 2, pp. 223-231.

West, J., Salter, A., Vanhaverbeke, W. and Chesbrough, H. (2014), “Open innovation: The next decade”, Research Policy, Elsevier B.V., Vol. 43 No. 5, pp. 805-811.

Xiaobao, P., Wei, S. and Yuzhen, D. (2013), "Framework of open innovation in SMEs in an emerging economy: firm characteristics, network openness, and network information", International Journal of Technology Management, Vol. 62 No. 2/3/4, pp. 223-250.

Yun, J., Won, D.K., Hwang, B.Y., Jung, W. and Kim, D.-H. (2013), "Exploration of the Effects of Open Innovation Policies on National Innovation Systems through System Dynamics Simulation", The 31st International Conference of the System Dynamics Society, Cambridge, Massachusetts, p. 24.

Zanzouri, C. and Francois, J.-C. (2013), "Knowledge management practices within a collaborative R\&D project: Case study of a firm in a cluster of railway industry”, Business Process Management Journal, Vol. 19 No. 5, pp. 819-840.

Zapata, C. and Nieuwenhuis, P. (2010), "Exploring innovation in the automotive industry: new technologies for cleaner cars", Journal of Cleaner Production, Wiley Online Library, Vol. 18 No. 1, pp. 14-20.

Zhao, F. (2014), "A holistic and integrated approach to theorizing strategic alliances of small and medium-sized enterprises", Business Process Management Journal, Vol. 20 No. 6, pp. 887-905. 


\section{Appendix}

Table A1. Constructs and measurement items.

\begin{tabular}{|c|c|c|c|c|c|}
\hline ID & Variables & Loads & ID & Constructs & Loads \\
\hline \multirow[t]{6}{*}{$1^{\mathrm{b}}$} & $\underline{\text { Internal R\&D }}(\alpha=0.894, \mathrm{CR}=0.921, \mathrm{AVE}=0.702)^{\mathrm{a}}$ & & $6^{\mathrm{b}}$ & Innovation phase variety $(\alpha=0.82, \mathrm{CR}=0.874, \mathrm{AVE}=0.585)$ & \\
\hline & We use in-house $R \& D$ to increase the knowledge for developing new products & 0.874 & & We collaborate with our partners during the following stages: & \\
\hline & We have continuously chosen to hire permanent R\&D staff in-house & 0.838 & & Idea generation/inspiration & 0.632 \\
\hline & We conduct basic $R \& D$ as a regular activity & 0.828 & & Experimentation & 0.766 \\
\hline & We invest economic or human resources in internal R\&D & 0.913 & & Engineering & 0.857 \\
\hline & We produce intellectual property like patents or trademarks & 0.725 & & Manufacturing & 0.854 \\
\hline \multirow[t]{7}{*}{$2^{b}$} & Inbound practices $(\alpha=0.846, \mathrm{CR}=0.886, \mathrm{AVE}=0.565)$ & & & Commercialization & 0.689 \\
\hline & We buy external R\&D services & 0.753 & $7^{b}$ & Innovativeness $(\alpha=0.92, \mathrm{CR}=0.904, \mathrm{AVE}=0.725)$ & \\
\hline & We buy external knowledge such as patents or licenses & 0.751 & & We have reduced innovation risks & 0.833 \\
\hline & We acquire advanced machinery, equipment or software to produce new products & 0.737 & & We have reduced new product/process development cost & 0.889 \\
\hline & We perform trend and technology scouting & 0.797 & & We have reduced time to market & 0.899 \\
\hline & We buy technical or scientific services & 0.788 & & We have introduced new or significantly improved products or services & 0.874 \\
\hline & We train our personnel externally & 0.779 & & We have introduced new process of producing our products or services & 0.779 \\
\hline \multirow[t]{7}{*}{$3^{\mathrm{b}}$} & Outbound practices $(\alpha=0.864, \mathrm{CR}=0.896, \mathrm{AVE}=0.592)$ & & & We have opened new markets & 0.83 \\
\hline & We commercialize technology developed or improved inside our firm & 0.783 & $8^{\mathrm{c}}$ & $\underline{\text { Economic performance (formative scale) }}$ & \\
\hline & We sell our intellectual property (IP) such as patents, copyrights or trademarks & 0.805 & & In comparison to your own firm's performance (last 3 years) & 0.623 \\
\hline & We offer royalty agreements to other firms so they can use our IP & 0.804 & & To the average performance of firms in your industry (last 3 years) & 0.12 \\
\hline & We sell innovation projects developed inside our firm & 0.733 & & To the current average performance of firms in your industry & 0.69 \\
\hline & We create spin-off firms to profit from internally developed ideas & 0.574 & $9^{d}$ & Environmental performance (formative scale) & \\
\hline & We sell technical or scientific services based on our expertise & 0.841 & & Using recycled materials or with low environmental impact in its products & 0.884 \\
\hline \multirow[t]{10}{*}{$4^{b}$} & $\underline{\text { Partner variety }}(\alpha=0.739, \mathrm{CR}=0.819, \mathrm{AVE}=0.554)$ & & & Adopting initiatives to be energy efficient or using renewable energy & 0.866 \\
\hline & Our firm collaborates with the following stakeholders: & & & Considering trends in mobility such as electric cars & 0.552 \\
\hline & Universities & 0.727 & & Adopting initiatives to reduce waste or recycling & 0.933 \\
\hline & Innovation intermediaries & 0.77 & & Mitigating environmental impacts of our products or processes & 0.787 \\
\hline & Customers/clients & 0.646 & $10^{\mathrm{d}}$ & $\underline{\text { Social performance (formative scale) }}$ & \\
\hline & Suppliers & 0.688 & & Adopting an approach to social responsibility & 0.851 \\
\hline & Industry or trade associations & 0.656 & & Being concerned about employees' health and safety & 0.704 \\
\hline & Firms from other industries & 0.672 & & Embracing the idea of diversity and equal opportunity & 0.654 \\
\hline & Government $^{\mathrm{e}}$ & - & & Providing training and career development to employees & 0.964 \\
\hline & Competitors $^{\mathrm{e}}$ & - & & Evaluating and managing the impacts of our operations in the community & 0.707 \\
\hline
\end{tabular}


$5^{\mathrm{b}}$ Content variety $(\alpha=0.873, \mathrm{CR}=0.908, \mathrm{AVE}=0.663)$

We collaborate with our partners while they provide us with the following:

Leading edge of technology

Reliable deliveries

System responsiveness - supply chain capability

Project management capability

Improvement capability

a. $\alpha=$ Scale reliability coefficient; $\mathrm{CR}=$ composite reliability; AVE $=$ average variance extracted

b. Five-point Likert-type scale (1) strongly disagree (7) very disagree.

c. Five-point Likert-type scale (1) much worse (7) much better.

d. Five-point Likert-type scale (1) no influence (7) major influence.

e. Scale item dropped during analysis by means of a Confirmatory Factor Analysis. 